\title{
ALGUNAS APLICACIONES DE ECONOMÍA AMBIENTAL EN CHILE*
}

\author{
Raúl O'Ryan, Manuel Díaz y Andrés Ulloa
}

Este artículo presenta algunos resultados de investigaciones realizadas en el ámbito de la economía ambiental y desarrolladas en la última década por el Programa de Gestión y Economía Ambiental (PROGEA). Los casos presentados — que ilustran los diversos enfoques desarrollados recientemente en este campo- muestran cómo un razonable uso del instrumental económico en el ámbito del medio ambiente permite hacer propuestas y recomendaciones valiosas de política pública y finalmente tomar mejores decisiones.

Raúl O'Ryan G. Departamento de Ingeniería Industrial, Universidad de Chile.

Manuel Díaz R. Investigador del Programa de Gestión y Economía Ambiental (PROGEA), Universidad de Chile.

ANDRÉs UlloA O. Investigador del Programa de Gestión y Economía Ambiental (PROGEA), Universidad de Chile.

* Versión revisada del trabajo presentado en el Encuentro Anual de Economistas de Chile que se realizó en Punta de Tralca en septiembre de 2003. 


\section{INTRODUCCIÓN}

E

este artículo nos proponemos presentar aplicaciones de economía ambiental en Chile — nuestras aplicaciones-, bajo el supuesto (buenos somos los economistas para hacer supuestos) de que lo realizado en esta última década tiene alguna coherencia, sigue una línea y en definitiva se puede aprender algo de lo que es la economía ambiental a partir de lo hecho. Sin embargo, como bien sabemos los que nos dedicamos a la investigación, los proyectos que se realizan por lo general son el resultado del azar, combinándose aleatoriamente conversaciones motivadoras que nos enamoran de algún tema, invitaciones hechas por colegas, inquietudes personales, la lectura de un trabajo que nos encandila, oportunidades de financiamiento, estados de ánimo, etc. Si hay un hilo conductor, es el hecho de que se trata de problemas ambientales. Por otro lado, el campo de la economía ambiental es tan vasto que difícilmente se puede llegar a visualizarlo en su conjunto a partir de aplicaciones particulares. En resumen, no es evidente que haya una coherencia en lo realizado y estamos seguros de que sólo presentaremos una parte pequeña del amplio campo de acción de esta subdisciplina aplicada ${ }^{1}$.

Debemos reconocer, además, que nuestro desarrollo en el campo de la economía ambiental, en realidad, es sólo una excusa para aplicar los conceptos microeconómicos en un área de alta complejidad e impacto en la que es fácil olvidarse que hay trade-offs (muy difícil de evaluarlos) y que los incentivos importan, en la que hay ganadores y perdedores (las soluciones win-win son pocas) y que el diablo está en los detalles que se nos olvidan al diseñar. Es un área en que lo interdisciplinario es fundamental y en que los modelos aplicados son escasos pero muy necesarios para apoyar la toma de decisiones.

Habiendo hecho estos descargos, precisamos que nuestra aproximación al tema de la economía ambiental es aplicado, en el sentido de que hemos intentado generar modelos conceptuales y antecedentes duros que apoyen propuestas de políticas. Ello implica tratar de entender los mercados específicos, conversar con los involucrados, recolectar información primaria, conocer los aspectos técnicos. En verdad, en nuestra realidad de país — aún - en desarrollo la disponibilidad de información para apoyar decisiones es escasa, lo que nos obliga a salir a buscarla, a ensuciarnos las

${ }^{1}$ De la teoría microeconómica básica surgen varias subdisciplinas fundamentales, por ejemplo, finanzas públicas, organización industrial y comercio internacional, y subdisciplinas aplicadas, tales como economía del trabajo, economía de la salud, economía y derecho y economía ambiental, entre otras. 
manos. Compartimos en este sentido el planteamiento hecho por el profesor Darrell Hueth de la Universidad de Maryland en una conferencia reciente, en que señala que "en cierto sentido es afortunado que en estos países sea poco probable encontrar datos secundarios"..., ya que nos obliga a conversar, a salir a terreno ${ }^{2}$.

Queremos señalar, además, que a nuestro juicio las recetas simples o un enfoque tipo piecemeal no se aplican muchas veces en este campo (y en general en ninguno en la economía). Generalmente nos encontramos en situaciones en que se aplica el teorema del segundo óptimo, lo que significa que las distorsiones de difícil corrección en un mercado obligan a distorsionar otros mercados, para lograr una asignación eficiente de recursos. Por una parte, hay políticas públicas, tales como impuestos distorsionadores, subsidios y protecciones; y por otra, en el sector privado hay externalidades de todo tipo y comportamientos no competitivos. Como sabemos, esto obliga a hacer evaluaciones empíricas para comparar los costos y beneficios de las políticas que se busca aplicar. En particular se necesitan modelos más o menos sofisticados para hacer las evaluaciones. Arrow, Dasgupta y Mäler, en el trabajo reciente "Welfare Economics in Imperfect Economies" (2002), señalan en este sentido que es necesario avanzar en la generación de indicadores teóricamente correctos de bienestar intertemporal cuando hay distorsiones en la economía, así como en su evaluación empírica, basada en modelos de equilibrio general o al menos entre varios sectores.

Finalmente es importante precisar el ámbito específico en que centraremos este artículo. Primero es necesario destacar que por lo general se habla de la "economía ambiental $y$ de recursos naturales", para hacer una clara distinción entre los problemas ambientales o de calidad ambiental y los problemas asociados al manejo óptimo de recursos naturales. Los temas tratados en ambas áreas son diferentes, si bien el enfoque económico normativo general con que se abordan es similar: se busca definir una política socialmente óptima y luego establecer los instrumentos que permitan acercarse a esta política óptima. La economía ambiental aborda los temas de contaminación del aire, agua, suelos, el ruido; los problemas globales y regionales, como el calentamiento global y la lluvia ácida y la destrucción de la capa de ozono; el manejo de sustancias tóxicas. La economía de recursos se preocupa de los recursos renovables, como el caso de los bos-

\footnotetext{
${ }^{2}$ Por otra parte, observamos, no sin algo de envidia, el trabajo de colegas en otras latitudes que pueden, desde sus oficinas, utilizando poderosas bases de datos secundarias en línea, realizar corridas de modelos haciendo supuestos de funciones de utilidad flexibles y competencia perfecta, las que luego se publican en los mejores journals de economía.
} 
ques, el agua y la pesca; y de los no renovables, como el cobre; de la producción de alimentos, del petróleo y la energía.

Segundo, hay temas transversales que cruzan las diversas áreas tales como los criterios de selección de instrumentos para la regulación ambiental, que incluyen el problema de la incertidumbre y diseño de los mismos además de su eficiencia e impacto distributivo; evaluaciones parciales vs evaluaciones generales; el problema de la optimalidad intertemporal (eficiencia dinámica vs. eficiencia estática); y técnicas de valoración.

Nuestra área de trabajo ha estado centrada en los últimos años fundamentalmente en temas de economía ambiental, criterios de selección de instrumentos y equilibrio general. Por tanto, en las secciones que siguen presentaremos los resultados obtenidos en nuestras investigaciones para Chile en cada uno de estos ámbitos, así como algunas conclusiones y recomendaciones que surgen a partir de nuestra experiencia de más de una década en estos temas en el Programa de Gestión y Economía Ambiental (PROGEA). Cabe destacar que en forma creciente académicos chilenos están publicando en journals importantes acerca de estos temas. Específicamente en la sección 2 se presentan tres casos relacionados con enfoques de regulación. Luego, en la sección 3 se discute un nuevo modelo para entender los instrumentos regulatorios que afectan a las empresas cuyo accionar tiene efectos sobre el medio ambiente y se presenta un caso. Finalmente la sección 4 discute la aplicación de un modelo de equilibrio general para evaluar políticas ambientales. La sección 5 presenta las principales conclusiones.

\section{ENFOQUES PARA LA REGULACIÓN AMBIENTAL: CASOS}

El mercado puede fallar de múltiples maneras tratándose de problemas ambientales. Por una parte están las externalidades, que son efectos no deseados - y no compensados - de una actividad productiva o de consumo. Es característico que lleven a un exceso de contaminación. Por otra, está la insuficiente provisión de bienes y servicios ambientales con carácter de bien público, tales como la biodiversidad y bosques y la sobreexplotación de bienes de libre acceso, como la pesca, la explotación de aguas subterráneas o los yacimientos de gas.

Los enfoques de regulación normativos tradicionales proponen dos modos de enfrentar estas fallas de mercado. El primer enfoque es el análisis costo-beneficio, basado en el enfoque pigouviano, busca las formas de 
acercar los costos sociales y privados aceptando que existe una imperfección en el mercado. A partir de ello se proponen instrumentos correctivos que maximizan el bienestar social. El segundo enfoque, de derechos de propiedad, basado en Coase, se concentra en explicar por qué existe la imperfección y en las formas de superarla, por lo general disolviendo el problema. Se propone para ello la creación de los mercados ausentes, que serían el origen del problema. Ambos enfoques son optimizantes en el sentido de que buscan un resultado eficiente. Si bien éstos son conceptualmente atractivos (en particular para los economistas), son difíciles de aplicar en la práctica, considerando los requerimientos de información y dificultades de implementación.

La práctica de los tomadores de decisión ha llevado además al desarrollo de tres enfoques alternativos. Éstos no buscan el resultado óptimo, pero sí avanzar en el logro de mejoras ambientales. Por una parte el enfoque de costo-efectividad busca identificar los instrumentos que permitan el logro de las metas ambientales establecidas al menor costo posible. Este enfoque $-\mathrm{y}$ la propuesta relacionada de utilizar permisos transables - ha tenido gran aceptación entre los economistas.

Luego, el análisis de riesgos es un enfoque que busca establecer metas aceptables en base a equilibrar diversos atributos de interés para el regulador, tales como costos, riesgos, aspectos éticos, sociales y legales. Finalmente, en la última década se han desarrollado con fuerza los enfoques o acuerdos voluntarios. Éstos son compromisos de parte de empresas contaminantes de mejorar su desempeño ambiental que no son exigidos por la legislación. Por tanto, en contraste con los enfoques regulatorios anteriores, no se aplican necesariamente a todas las fuentes emisoras. En particular no se aplican a aquellas fuentes que no se benefician de participar en los programas, o cuyos costos son mayores que los beneficios. Por ejemplo, en el año 2000 sólo en Estados Unidos 13.000 firmas, organizaciones no gubernamentales y agencias locales estaban involucradas en acuerdos voluntarios promovidos por la Agencia de Protección Ambiental (EPA). Si bien estos enfoques son prácticos, son mirados con suspicacia por parte de los economistas, ya que no aseguran un resultado eficiente.

Es interesante constatar que algunos de estos enfoques se están aplicando en Chile y que la economía se está usando en forma creciente en el campo ambiental. A continuación se discuten algunas aplicaciones en las que nos ha tocado estar involucrados y el aporte que se ha hecho desde una óptica económica. 


\subsection{Caso 1: Costo efectividad de instrumentos para reducir las emisiones en Santiago ${ }^{3}$}

La primera aplicación en que nos tocó participar fue en la evaluación de la de costo efectividad del uso de permisos transables para Santiago, tema muy discutido en la literatura internacional de la época. En Santiago se estaba implementando desde 1992 este instrumento —el sistema de compensaciones-, lo que lo transformaba en una de las primeras aplicaciones urbanas significativas en el mundo. Este sistema entrega a cada fuente puntual existente de la ciudad un total máximo para emitir, y le autoriza a emitir en exceso si compensa éste comprando cupos de contaminación a fuentes que reducen más allá de su meta individual. Además obliga a cada fuente nueva a entrar emitiendo cero, ya que debe compensar todas sus emisiones.

La información disponible era muy escasa. Recién se estaban generando los inventarios de emisiones, por lo que la información sobre fuentes emisoras (ubicación, emisiones) y las metodologías de cálculo eran deficientes. Para hacer este tipo de análisis es necesario además contar con información de opciones de control, lo que éstas reducen y sus costos. Finalmente se requieren modelos que permitan relacionar las emisiones con las concentraciones, lo que se estaba trabajando de manera incipiente en la época. Hubo que construir mucha de la información y hacer supuestos fuertes para los parámetros donde aquélla no estaba disponible. La información y los modelos son un problema hasta el día de hoy en este ámbito.

La evaluación empírica exigió, para las 1.441 fuentes involucradas y 289 zonas en que se dividió la ciudad, resolver el siguiente problema:

$$
\begin{gathered}
\min \sum_{i=1}^{n} c^{i}\left(e^{i}\right) \\
\text { s.a. } \\
Q=f\left(e^{i}, \ldots \ldots . . e^{n}\right) \\
Q \leq Q^{*} \\
e^{i} \geq 0 i=11, \ldots \ldots . ., n,
\end{gathered}
$$

\footnotetext{
${ }^{3}$ Resumido a partir de O’Ryan (1996). Disponible en www.dii.uchile/progea/
} 
donde $e^{i}$ son las emisiones por fuente $i$ después que se aplica la política i; $c^{i}\left(e^{i}\right)$ es el costo total de abatimiento para la fuente $i$ de reducir a $e^{i} ; Q$ es un vector del estándar de concentración ambiental en las ubicaciones del sector $\mathrm{K} ; \mathrm{f}\left(e^{l}, \ldots \ldots \ldots . . ., e^{n}\right)$ es un modelo de sistemas naturales que relaciona los niveles de emisiones para todas las fuentes con las concentraciones ambientales en cada receptor; y $Q^{*}$ es un vector de los niveles de concentración ambientales.

Se consideraron cuatro instrumentos ${ }^{4}$-dos de mercado (SPA y SPE) y dos de regulación directa (PER y STD) — y se compararon los costos asociados a cumplir diferentes metas. Cabe señalar que SPA es la aplicación teóricamente óptima (de mínimo costo) de permisos transables. SPE es una aplicación subóptima que acepta intercambiar permisos sin importar la localización de las fuentes. STD en cambio es la aplicación de estándares de emisión uniformes a las fuentes y PER exige reducción porcentual igual a cada fuente. Los resultados se resumen en la Figura $\mathrm{N}^{\circ} 1$.

FIGURA $N^{\circ} 1: \quad$ COSTO EFECTIVIDAD DE INSTRUMENTOS REGULATORIOS EN SANTIAGO

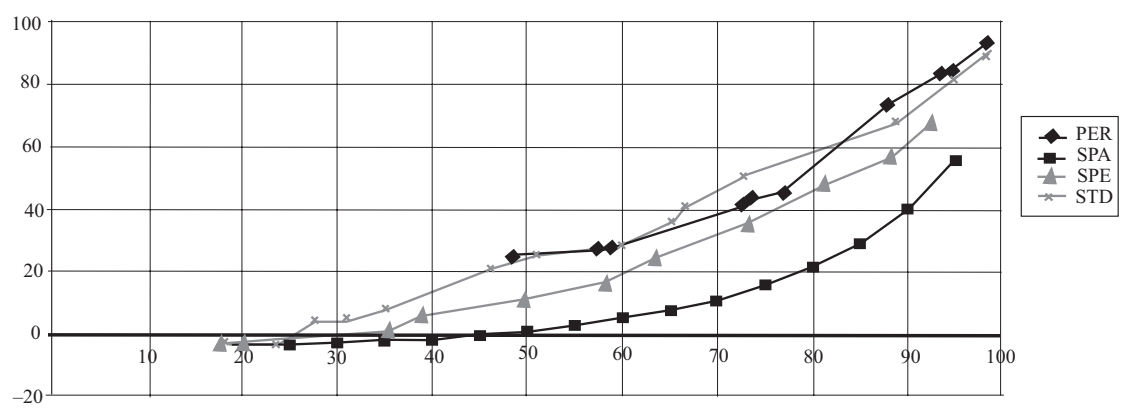

Se concluyó que SPE —el sistema propuesto para Santiago - tiene un desempeño peor que SPA, sin embargo en general mejor que el de PER y STD hasta reducciones de un $65 \%$. Esto, siempre que se realicen todos los intercambios. Estos resultados, que estaban en la línea de lo obtenido en otros estudios para Estados Unidos, respaldan la aplicación del instrumento propuesto.

Cabe preguntarse: ¿qué buscaban las autoridades al implementar este sistema? ¿Para qué se estaba implementando un esquema flexible si ni

${ }^{4}$ SPA: sistema de permisos ambientales; SPE: sistema de permisos de emisión; PER: porcentaje de reducción de emisiones igual para todas las firmas; STD: estándar de emisión igual para todas las firmas. 
siquiera se había evaluado su conveniencia? ¿Se lograron los resultados esperados? No hay documentos que detallen estos objetivos ni una evaluación de su desempeño, pero en conversaciones con las autoridades de la época surgieron los siguientes objetivos implícitos:

(1) usar instrumentos de mercado costo efectivos, esto casi a nivel de dogma;

(2) aceptación de la regulación por parte del sector privado;

(3) mantener en un mínimo la intervención y discrecionalidad gubernamentales;

(4) respeto a los derechos de propiedad;

(5) simplicidad en el diseño y facilidad de uso;

(6) mantener bajos — pero efectivos- los costos de control y aplicación;

(7) poner un tope a las emisiones totales de calderas y procesos industriales, permitiendo, no obstante, el ingreso de fuentes nuevas en el sistema.

Los resultados observados seis años después de aplicar un sistema mucho más modesto que el propuesto eran poco alentadores. Hasta 1998, las tareas de descontaminación habían resultado exitosas, pero el sistema de permisos no. Puede argumentarse que, aun en ausencia del sistema, se habría obtenido la mayor parte de las reducciones observadas en el período, las que obedecerían a la llegada del gas natural, a la obligación de las fuentes de cumplir con una "norma de decencia", que en la práctica obligaba a no usar combustibles sólidos o altamente contaminantes ${ }^{6}$, y al interés de las fuentes de evitar restricciones a su operación durante las preemergencias, lo que se lograba emitiendo menos ${ }^{7}$.

Las fuentes existentes no habían utilizado la mayor flexibilidad, es decir, no se había desarrollado un mercado de transacciones. Las fuentes nuevas casi no estaban compensando sus emisiones, a pesar de que la legislación lo exigía y que había créditos disponibles. $70 \%$ de las emisiones de los procesos industriales no era parte del sistema, debido a que problemas técnicos impedían estimar sus emisiones ${ }^{8}$. Por eso, tales emisio-

${ }^{5}$ De $112 \mathrm{mg} / \mathrm{m}^{3}$.

${ }^{6}$ Como el carbón, la leña o el petróleo pesado.

${ }^{7}$ Un punto importante es establecer si el gas natural habría llegado a Santiago si los requisitos ambientales no lo hubieran tornado necesario. En ausencia de un sistema de permisos, ¿habrían impuesto las autoridades normas estrictas, factibles de cumplir solamente con gas natural, un combustible no disponible en ese momento?

${ }^{8}$ Para un análisis más acabado, véase O'Ryan (2002), Montero et al. (2001) y O'Ryan (1999). 
nes no estaban bajo control. Así, los objetivos implícitos antes señalados no se estaban cumpliendo: no había costo efectividad y las emisiones de fuentes nuevas no estaban bajo control. Adicionalmente, el sistema sufrió constantes cambios, incluso antes de entrar en plena vigencia, lo que decepcionó parcialmente a los empresarios.

Si bien desde 1999 a la fecha este mercado ha empezado a funcionar mejor —en particular las fuentes nuevas están compensando sus emisiones-, se siguen observando altos costos de transacción, incertidumbre regulatoria e insuficiencias administrativas que dificultan que este tipo de instrumentos opere con la eficiencia teórica prevista. Quizás el resultado más importante es que ha permitido imponer metas al total de emisiones de cada tipo de fuente sin que ello haya implicado que no entren más fuentes al sistema.

Cabe señalar que hoy el análisis costo efectividad es bastante menos novedoso. No es aceptable tan fácilmente como una tesis de doctorado, a no ser que existan contribuciones notables. De hecho, los ejercicios más típicos de este tipo de modelamiento se pueden obtener en memorias de pregrado (y lo hemos hecho). Lo que se está investigando con más detención es precisamente cómo reducir los problemas que dificultan que estos mercados se desarrollen y operen.

\subsection{Caso 2: Análisis riesgo-costo de una regulación ambiental para el arsénico ${ }^{9}$}

Chile presenta altos niveles de arsénico en el aire y en el agua, en particular en el Norte. Esto se debe tanto a las altas concentraciones que existen en forma natural en el suelo y en los ríos como a las emisiones de las múltiples fundiciones de cobre del país. Aproximadamente 370 mil personas reciben el impacto de las emisiones de arsénico en el aire y 300 mil el de las emisiones en el agua. El arsénico inorgánico ha sido catalogado como una sustancia cancerígena por la Agencia Internacional de Investigaciones del Cáncer, en particular como causante de cáncer de pulmón ${ }^{10}$, y este daño sería independiente de la vía de ingesta.

En la Segunda Región, la tasa de mortalidad por este tipo de cáncer supera 2,6 veces el promedio nacional. Por ello, desde comienzos de los noventa, el Ministerio de Salud, venía proponiendo una norma de calidad

${ }^{9}$ Resumido a partir de O’Ryan y Díaz (2000), pp. 115-134. Disponible en www.dii.uchile.cl/progea/pub-en.htm

${ }^{10}$ Existe alguna evidencia de que el arsénico que ha contaminado el agua produce además cáncer en otros órganos, tales como los riñones, el hígado y la vejiga. 
muy estricta de $0,05 \mu \mathrm{g} / \mathrm{m}^{3}$ como promedio anual para el arsénico en el aire. Ello generó una polémica bastante aguda con el Ministerio de Minería y las empresas afectadas — cinco de las siete más grandes son estatales—, lo que finalmente llevó a la proposición, a fines de 1993, de un proyecto liderado por la Universidad de Chile ${ }^{11}$ para examinar el tema y hacer propuestas concretas. Aún así, en marzo de 1994, a través del decreto 477, el Ministerio de Salud publicó una norma de calidad que tuvo que ser derogada a los pocos meses por oposición de las empresas y del Ministerio de Minería. Como veremos, esta oposición tenía fundamento.

Las preguntas centrales que se debían responder eran: 1) ¿qué instrumento aplicar: norma de calidad - la cual, de acuerdo con nuestra legislación, debía ser uniforme para todo el país- o norma de emisión, que podía se diferenciada según el número de afectados y emisiones de cada fundición?, y 2) ¿qué valor de norma aplicar? Adicionalmente el proyecto entregó antecedentes para analizar si era más barato regular el arsénico del aire o el del agua.

\section{Metodología de análisis}

Para hacer el análisis se propuso utilizar una metodología de evaluación riesgo-costo, la que se presenta esquemáticamente en la Figura $\mathrm{N}^{\circ} 2$.

FIGURA $\mathrm{N}^{\circ}$ 2: $\quad$ CURVA DE EVALUACIÓN RIESGO-COSTO

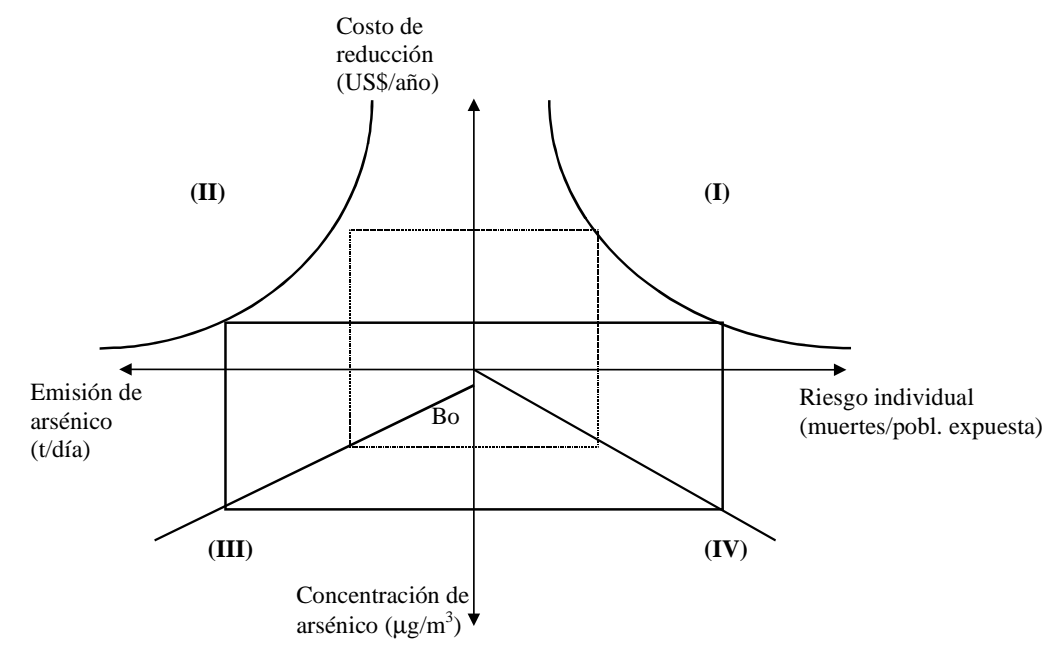

${ }^{11}$ Proyecto FONDEF 2-24. 
Esta metodología se aplica a cada fuente emisora. En primer lugar se identifica un rango de valores posibles para la concentración de arsénico. Luego, cada uno de estos valores se relaciona con un nivel de emisión (cuadrante III). Para ello es necesario utilizar un modelo de dispersión o factores de transferencia. Es fundamental conocer el nivel base natural (Bo), ya que la concentración resultante de las emisiones es la suma de este nivel base y el aporte respectivo de la fuente. Este nivel de emisión es la meta para la fundición, que permitiría cumplir con la calidad ambiental que se evalúa. Para lograr este nivel de emisión, cada fuente debe aplicar opciones de reducción e incurrir en un costo (cuadrante II). Finalmente, la concentración meta determina, por medio del riesgo unitario, un riesgo individual para cada localidad afectada por cada fuente (cuadrante I). Ello permite estimar, a partir de la población expuesta a cada nivel de concentración, las muertes que se evitarán al aplicar el estándar. De esta forma se obtiene, para cada nivel de concentración, un riesgo implícito y muertes evitadas por localidad, y el costo en que incurre cada fundición para lograr esa calidad del aire.

\section{Resultados evaluación riesgo-costo}

Los resultados muestran que hay opciones win-win que logran significativas mejoras en salud a muy bajo costo, e incluso con beneficios netos para las fundiciones involucradas. Sin embargo los costos aumentan rápidamente al hacerse más restrictiva la norma de calidad, mientras que los beneficios adicionales en salud son muy bajos.

De la Figura $\mathrm{N}^{\circ} 3$ se desprende que es posible imponer valores de la norma entre $2,5 \mu \mathrm{g} / \mathrm{m}^{3}$ y $0,3 \mu \mathrm{g} / \mathrm{m}^{3}$ con un beneficio neto para las firmas si cumplen con la norma propuesta ${ }^{12}$. A partir de valores de la norma menores que $0,3 \mu \mathrm{g} / \mathrm{m}^{3}$ y hasta $0,15 \mu \mathrm{g} / \mathrm{m}^{3}$, los costos anuales de cada nivel posible de la norma toman valores positivos intermedios entre US\$ 35 millones y US\$ 38 millones. Para una norma inferior a $0,15 \mu \mathrm{g} / \mathrm{m}^{3}$, los costos crecen significativamente y se llegan a elevar por sobre los US\$ 100 millones anuales ${ }^{13}$. Las muertes estadísticas evitadas cada año decrecen al

${ }^{12}$ Esto se explica por el hecho de que algunas de las opciones permiten una mayor recuperación de cobre y de ácido sulfúrico del proceso, lo que incrementa los ingresos de las fundiciones, además de una reducción de los costos de operación. Con ello, a una tasa de descuento del $12 \%$, las opciones aplicadas permiten un valor presente positivo. Es probable que las empresas tengan mejores usos alternativos para sus recursos de inversión, que les reporten una tasa de retorno superior al $12 \%$.

${ }^{13}$ Esto se explica fundamentalmente por el hecho de que, con estas normas, algunas de las fundiciones más grandes del país deben cerrar su operación, ya que el valor de concentración exigido es inferior al nivel base natural 
FIGURA N ${ }^{\circ}$ 3: $\quad$ COSTOS DE REDUCCIÓN PARA DISTINTOS VALORES DE NORMA DE CALIDAD DE ARSÉNICO

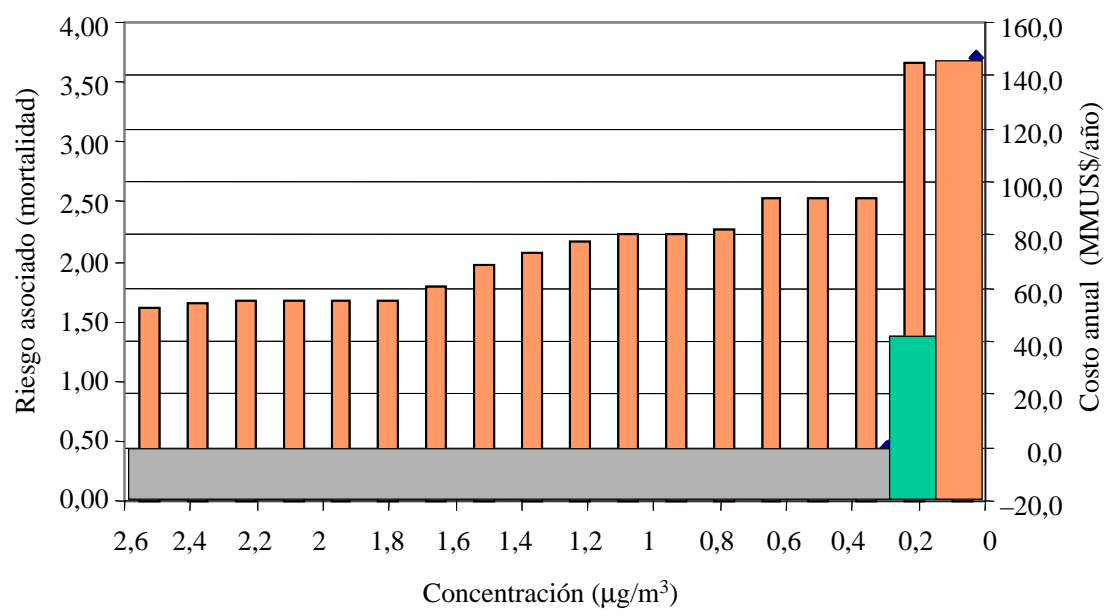

Riesgo asociado $\prec$ Costo anual

imponer una norma más exigente, pero ya no varían para valores de calidad menores que $0,15 \mu \mathrm{g} / \mathrm{m}^{3}$. Luego, una norma de calidad más exigente no tiene sentido económico.

¿Tiene sentido una norma de calidad única? Un examen permite concluir que el impacto de las diferentes normas es diferente en cada fundición. En efecto, el Cuadro $\mathrm{N}^{\circ} 1$ presenta el costo, las emisiones y la concentración que se logra en el punto de máximo impacto para cada fundición de los diferentes niveles potenciales de la norma.

Como se aprecia en el Cuadro $\mathrm{N}^{\circ} 1$, en muchas localidades, niveles naturales altos de arsénico hacen muy costoso o simplemente imposible el lograr estándares muy exigentes. Los resultados obtenidos sugieren la necesidad de regular caso a caso cada fuente - por medio de una norma de emisión - en vez de utilizar un instrumento único (norma de calidad), ya que una reglamentación pareja es impracticable, extremadamente cara, o deja sin protección suficiente a zonas importantes. Cabe destacar que, para el valor de norma propuesto por el Ministerio de Salud $\left(0,05 \mu \mathrm{g} / \mathrm{m}^{3}\right)$, cuatro de las siete fundiciones no son capaces de cumplir ni siquiera dejando de operar. Estos resultados se usaron para establecer en 1997 normas de emisión diferenciadas para fundiciones, las que hoy están en plena vigencia. 
CUADRO N ${ }^{\circ}$ 1: IMPACTO EN FUNDICIONES DE DIFERENTES NIVELES DE NORMA DE CALIDAD PARA EL As

\begin{tabular}{|c|c|c|c|c|c|c|c|}
\hline Fundición & & \multicolumn{6}{|c|}{ Norma de calidad $\left(\mu \mathrm{g} / \mathrm{m}^{3}\right)$} \\
\hline & & 0,70 & 0,30 & 0,1 & 0,09 & 0,07 & 0,05 \\
\hline Fundición 1 & $\begin{array}{l}\text { Conc. anual } \\
\text { (MUS\$) } \\
\text { Emis. }(\mathrm{t} / \mathrm{día}) \\
\text { Conc. }\left(\mu \mathrm{g} / \mathrm{m}^{3}\right)\end{array}$ & $\begin{array}{l}0,4 \\
0,63 \\
0,35\end{array}$ & $\begin{array}{l}6,9 \\
0,49 \\
0,29\end{array}$ & $\begin{array}{r}37,4 \\
0,63 \\
0,10\end{array}$ & $\begin{array}{c}44,2 \\
0 \\
\text { No } \\
\text { cumple }\end{array}$ & $\begin{array}{c}44,2 \\
0 \\
\text { No } \\
\text { cumple }\end{array}$ & $\begin{array}{c}44,2 \\
0 \\
\text { No } \\
\text { cumple }\end{array}$ \\
\hline Fundición 2 & $\begin{array}{l}\text { Conc. anual } \\
\text { (MUS\$) } \\
\text { Emis. }(\mathrm{t} / \mathrm{dí}) \\
\text { Conc. }\left(\mu \mathrm{g} / \mathrm{m}^{3}\right)\end{array}$ & $\begin{array}{c}-8,9 \\
0,18 \\
0,08\end{array}$ & $\begin{array}{r}-8,9 \\
0,18 \\
0,08\end{array}$ & $\begin{array}{r}-8,9 \\
0,18 \\
0,08\end{array}$ & $\begin{array}{c}-8,9 \\
0,18 \\
0,08\end{array}$ & $\begin{array}{c}6,4 \\
0 \\
\text { No } \\
\text { cumple }\end{array}$ & $\begin{array}{c}6,4 \\
0 \\
\text { No } \\
\text { cumple }\end{array}$ \\
\hline Fundición 3 & $\begin{array}{l}\text { Conc. anual } \\
\text { (MUS\$) } \\
\text { Emis. }(\mathrm{t} / \mathrm{día}) \\
\text { Conc. }\left(\mu \mathrm{g} / \mathrm{m}^{3}\right)\end{array}$ & $\begin{array}{l}0 \\
0,83 \\
0,11\end{array}$ & $\begin{array}{l}0 \\
0,83 \\
0,11\end{array}$ & $\begin{array}{l}1,3 \\
0,76 \\
0,1\end{array}$ & $\begin{array}{l}2,6 \\
0,41 \\
0,06\end{array}$ & $\begin{array}{l}2,6 \\
0,41 \\
0,06\end{array}$ & $\begin{array}{l}3,3 \\
0,34 \\
0,05\end{array}$ \\
\hline Fundición 4 & $\begin{array}{l}\text { Conc. anual } \\
\text { (MUS\$) } \\
\text { Emis. }(\mathrm{t} / \mathrm{día}) \\
\text { Conc. }\left(\mu \mathrm{g} / \mathrm{m}^{3}\right)\end{array}$ & $\begin{array}{l}0 \\
0,12 \\
0,24\end{array}$ & $\begin{array}{l}0 \\
0,12 \\
0,24\end{array}$ & $\begin{array}{l}5,7 \\
0,03 \\
0,10\end{array}$ & $\begin{array}{l}9,6 \\
0,0 \\
0,08\end{array}$ & $\begin{array}{c}9,6 \\
0,0 \\
\text { No } \\
\text { cumple }\end{array}$ & $\begin{array}{c}9,6 \\
0,0 \\
\text { No } \\
\text { cumple }\end{array}$ \\
\hline Fundición 5 & $\begin{array}{l}\text { Conc. anual } \\
\text { (MUS\$) } \\
\text { Emis. }(\mathrm{t} / \mathrm{dí} a) \\
\text { Conc. }\left(\mu \mathrm{g} / \mathrm{m}^{3}\right)\end{array}$ & $\begin{array}{l}0 \\
0,24 \\
0,09\end{array}$ & $\begin{array}{l}0 \\
0,24 \\
0,09\end{array}$ & $\begin{array}{l}0 \\
0,24 \\
0,09\end{array}$ & $\begin{array}{l}0 \\
0,24 \\
0,09\end{array}$ & $\begin{array}{l}1,2 \\
0,16 \\
0,06\end{array}$ & $\begin{array}{r}3,6 \\
0,05 \\
0,03\end{array}$ \\
\hline Fundición 6 & $\begin{array}{l}\text { Conc. anual } \\
\text { (MUS\$) } \\
\text { Emis. }(\mathrm{t} / \mathrm{día}) \\
\text { Conc. }\left(\mu \mathrm{g} / \mathrm{m}^{3}\right)\end{array}$ & $\begin{array}{l}0 \\
0,07 \\
0,15\end{array}$ & $\begin{array}{l}0 \\
0,07 \\
0,15\end{array}$ & $\begin{array}{l}1,5 \\
0,03 \\
0,06\end{array}$ & $\begin{array}{l}1,5 \\
0,03 \\
0,06\end{array}$ & $\begin{array}{l}1,5 \\
0,03 \\
0,06\end{array}$ & $\begin{array}{l}7,9 \\
0,02 \\
0,04\end{array}$ \\
\hline Fundición 7 & $\begin{array}{l}\text { Conc. anual } \\
\text { (MUS\$) } \\
\text { Emis. }(\mathrm{t} / \mathrm{dí} a) \\
\text { Conc. }\left(\mu \mathrm{g} / \mathrm{m}^{3}\right)\end{array}$ & $\begin{array}{l}0 \\
0,81 \\
0,55\end{array}$ & $\begin{array}{l}1,9 \\
0,27 \\
0,27\end{array}$ & $\begin{array}{c}15,3 \\
0,0 \\
0,08\end{array}$ & $\begin{array}{c}15,3 \\
0,0 \\
0,08\end{array}$ & $\begin{array}{c}15,3 \\
0,0 \\
\text { No } \\
\text { cumple }\end{array}$ & $\begin{array}{c}15,3 \\
0,0 \\
\text { No } \\
\text { cumple }\end{array}$ \\
\hline
\end{tabular}

Nota: Achurados se presentan aquellos casos en que las fundiciones deben cerrar para alcanzar el valor de norma de calidad propuesta.

Finalmente, cabe preguntarse si conviene reducir concentraciones de As en el aire o en el agua. El Cuadro $\mathrm{N}^{\circ} 2$ permite concluir que el esfuerzo de reducir descargas al agua es más rentable socialmente que el de reducir emisiones al aire. El costo de reducir 3,7 vidas estadísticas anuales (v. e.) (2,6 v. e. al reducir las concentraciones de As en agua a 0,1 mg/l y 
1,1 v. e. al reducir las concentraciones de As en aire a $0,4 \mu \mathrm{g} / \mathrm{m}^{3}$ ) es apenas US\$ 11 millones, comparados con los US\$ 35 millones (y hasta US\$ 140 millones) de reducir en el aire.

Uno de los aspectos más relevantes que nos tocó abordar en este trabajo fue el de la economía política. La industria minera hizo un lobby intenso para impedir una norma de calidad ambiental que, como vimos, no tenía sentido económico. Por otro lado, la posición liderada por el Minsal era cerrada y con pocos fundamentos socioeconómicos e incluso de salud. A poco de haber comenzado con la investigación nos dimos cuenta de que las normas de calidad para este tipo de contaminantes tóxicos peligrosos sólo existían en países en que no causaban problemas. En aquellos países donde el arsénico era un problema se norma en forma más flexible de manera tal de evitar grandes, costosos y demorosos conflictos judiciales que finalmente producían la completa inacción. Aquí el papel de la universidad fue muy importante. Ello permitió mostrar que en forma seria se pueden generar modelos e información que permiten tomar buenas decisiones y aumentar el bienestar social.

En términos generales se puede concluir que la generación de una norma ambiental es un proceso complejo, que exige de modelos sofisticados y cuyo resultado es más eficiente en la medida en que se utilizan instrumentos más flexibles. Por otra parte, se ha podido aplicar una política sin necesidad de evaluar en términos monetarios los beneficios.

CUADRO N$^{\circ}$ 2: $\quad$ COSTOS Y BENEFICIOS DE REDUCIR EL ARSÉNICO EN EL AIRE Y EN EL AGUA

\begin{tabular}{ccc|ccc}
\hline \multicolumn{2}{c|}{ Agua } & Aire & \\
$\begin{array}{c}\text { Concentración } \\
\text { As (mg/l) }\end{array}$ & $\begin{array}{c}\text { Costo anual } \\
\text { (Miles de } \\
\text { US\$) }\end{array}$ & $\begin{array}{c}\text { Muertes } \\
\text { estadísticas } \\
\text { evitadas } \\
\text { (personas } \\
\text { por año) }\end{array}$ & $\begin{array}{c}\text { Concentración } \\
\text { As }\left(\mu \mathrm{g} / \mathrm{m}^{3}\right)\end{array}$ & $\begin{array}{c}\text { Costo anual } \\
\text { (Miles de } \\
\text { US\$) }\end{array}$ & $\begin{array}{c}\text { Muertes } \\
\text { estadísticas } \\
\text { evitadas } \\
\text { (personas } \\
\text { por año) }\end{array}$ \\
\hline & & & & & \\
0,04 & 0 & 0 & & & \\
0,03 & 10 & 0,88 & 0,40 & 383 & 1,13 \\
0,02 & 440 & 1,76 & 0,10 & 37.000 & 1,17 \\
0,01 & 10.910 & 2,64 & 0,08 & 44.243 & 1,33 \\
\hline
\end{tabular}




\subsection{Caso 3: Beneficios netos de reducir la contaminación en Santiago}

Desde 1994 la Ley de Bases del Medio Ambiente exige realizar un análisis de costos y beneficios a los diversos planes y normas ambientales que se aplican. Tanto el Plan de Descontaminación de Santiago de 1997 como los posteriores planes para fundiciones de cobre han incorporado este análisis. Por ello en 1997 la Universidad de Chile desarrolló un Manual para Evaluar Costos y Beneficios para Conama. La Universidad Católica ha estado desarrollando recientemente el modelo Apheba para Conama con este fin. Otras instituciones públicas han estado involucradas en este tipo de esfuerzos, como el Ministerio de Minería, Mideplán y la Sectra. Para esta última la Universidad de Chile ha desarrollado el modelo integrado de evaluación económica, MODEC, que opera en conjunto con un modelo de emisiones (MODEM), para evaluar los beneficios ambientales de políticas de transporte. Este tipo de análisis es muy útil y permite establecer si los costos en que se incurrieron son razonables a la luz de los beneficios que se obtienen. En teoría, la autoridad debiera elegir un nivel de reducción que maximice el beneficio neto (beneficios menos costos). El siguiente caso ilustra lo anterior.

Luego de la aplicación del Decreto 4 detallada en el caso 1, los empresarios han reclamando que en la última década las fuentes fijas han realizado un esfuerzo significativo de descontaminación y que no les corresponde hacer más. Por otro lado, y como se destaca en el caso 1, los instrumentos económicos permiten el logro de las metas ambientales al menor costo para las fuentes. Lo que no se dijo, sin embargo, es que este menor costo se logra por dos razones muy diferentes. Primero, la ganancia en eficiencia estática tradicional, que se logra al reducir las emisiones de las fuentes a las que les cuesta menos. Una segunda fuente de reducción de costos se logra porque los instrumentos flexibles permiten una menor reducción de emisiones a las fuentes participantes que lo que permiten los instrumentos de regulación directa. En efecto, al ser menos flexibles, estos últimos obligan en muchos casos a reducir más allá de la meta de calidad establecida en muchas zonas de la ciudad. Esto las hace más costosas para las fuentes, pero a la vez la mejora en calidad ambiental genera beneficios - a la salud, materiales, agricultura y estéticos- mayores. Como la meta propuesta para estas fuentes no se ha hecho en base a un análisis optimizante de costo-beneficio, cabe la duda de cómo se comparan los beneficios netos de aplicar cada tipo de instrumento. ¿Serán los beneficios ambientales de aplicar un instrumento de regulación directa suficientes como para más que compensar los mayores costos de los mismos? En un artículo 
reciente escrito en conjunto con José Miguel Sánchez se explora esta pregunta y de pasada da respuesta a los empresarios respecto de si su esfuerzo puede considerarse suficiente.

Para ello, siguiendo la metodología detallada en el caso 1, se comparan primero los costos de aplicar SPA, SPE y normas de emisión parejas (STD). Se utilizan datos más recientes pero se obtienen resultados similares en cuanto a que SPA es costo efectiva, SPE es de mayor costo y STD es la más costosa. Sin embargo, la reducción en concentraciones asociadas a cada instrumento es también diferente, como se observa en la Figura $\mathrm{N}^{\circ} 4$. SPA exige menores reducciones en las 17 celdas que SPE, y ésta menores reducciones que STD. Por tanto, los beneficios ambientales de STD serán mayores.

FIGURA N ${ }^{\circ}$ 4: $\quad$ CALIDAD DEL AIRE LOGRADA AL APLICAR INSTRUMENTOS QUE REDUCEN LAS CONCENTRACIONES EN 36\% EN LA PEOR CELDA (REDUCCIÓN META DESEADA $=100$ )

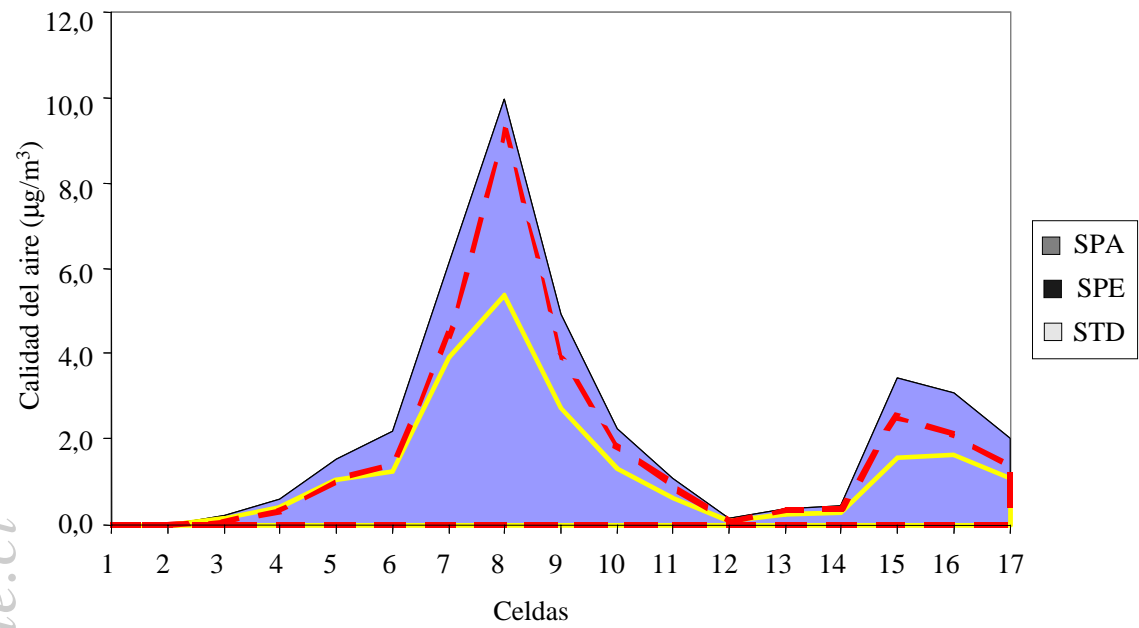

Para estimar estos beneficios es necesario identificar los daños que se evitan y luego valorarlos. La metodología de evaluación de beneficios en salud consiste en el uso de funciones-dosis respuesta que capturan los efectos en salud por la mejora en la calidad ambiental con respecto a la situación base. El siguiente Cuadro $\mathrm{N}^{\circ} 3$ presenta los valores utilizados para ello. 


\section{CUADRO $\mathrm{N}^{\circ}$ 3: $\quad$ COSTOS UNITARIOS DE EFECTOS EN SALUD}

Admisiones hospitalarias debido a enfermedades respiratorias

Fuente: Holz y Sánchez (2000). Los números han sido redondeados para evitar dar un sentido de falsa precisión.

Al anualizar los beneficios diarios obtenidos en el análisis de valoración y sumarlos a los costos se obtienen los beneficios netos. Éstos se aprecian en la Figura $\mathrm{N}^{\circ}$ 5. Se desprenden varias conclusiones interesantes. Primero, que el máximo beneficio social se logra reduciendo en $42 \%$ las emisiones utilizando SPE. Esto permite responder a los empresarios que aún es deseable hacer reducciones mayores. Segundo, que el instrumento SPA, que es el más costo efectivo, aparece como el de menor beneficio neto. SPE y STD permiten lograr un beneficio neto relativamente similar. Lo anterior se debe al hecho de que los beneficios en salud de las reducciones adicionales asociadas a éstos más que compensan las ganancias en eficiencia y costos del SPA ${ }^{14}$.

En este caso, la valoración entrega información respecto de la posibilidad de exigir mayores reducciones sumando los beneficios de diversos impactos en salud. Además confirma que utilizar SPE es una buena opción. En el caso 2 anterior bastaba considerar un solo efecto — cáncer de pulmón- para obtener los resultados que informaron la decisión de política, y por ello no fue necesario valorar. Para seguir avanzando en esta línea es crítico consensuar los valores de dosis-respuesta por utilizar para cada efecto y especialmente los valores por utilizar para ponerle un valor monetario a cada efecto (el "valor de la vida", por ejemplo).

${ }^{14}$ No debe concluirse a partir de esto que el SPA no es deseable. Aplicarlo como se ha hecho aquí, imponiendo que en cada una de las zonas (receptores) consideradas se debe cumplir una meta de calidad única, lleva a este resultado. Por cierto, se puede proponer un sistema SPA que replique las calidades obtenidas en cada celda utilizando STD o SPE y en este caso las ganancias en eficiencia de SPA permitirán obtener los mayores beneficios netos. 
FIGURA N ${ }^{\circ}$ 5: $\quad$ BENEFICIOS NETOS DE REDUCIR MATERIAL PARTICULADO EN SANTIAGO CONSIDERANDO DIFERENTES INSTRUMENTOS DE REGULACIÓN

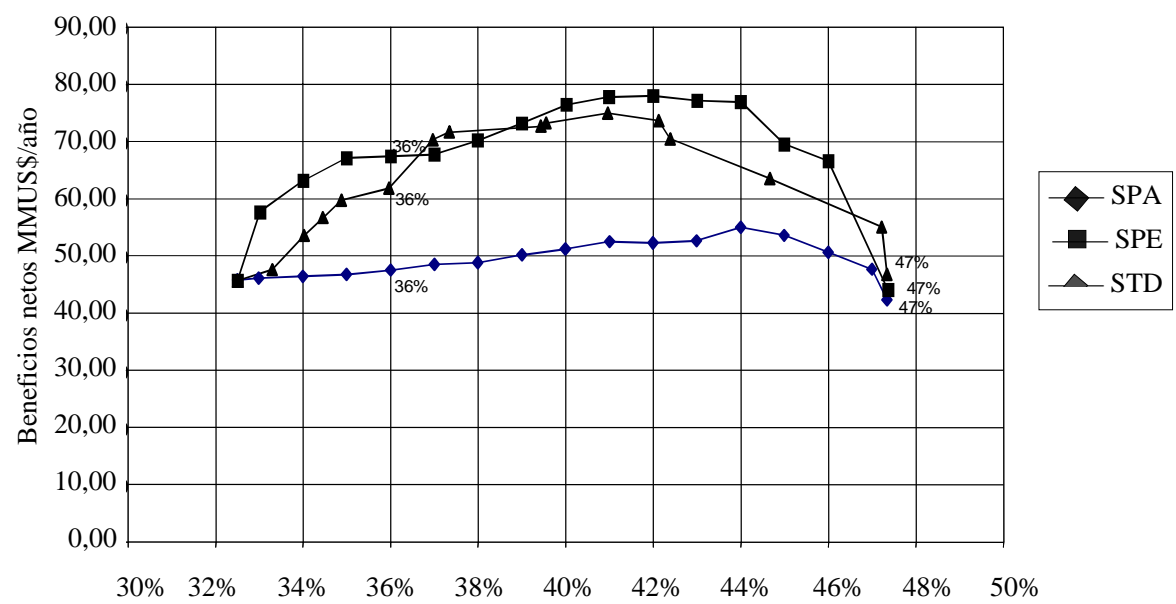

Disminución porcentual en relación con la peor celda

\section{INSTRUMENTOS DE REGULACIÓN AMBIENTAL:}

EL NUEVO MODELO Y CASOS PARA CHILE

Es ya un lugar común para los economistas ambientales la distinción entre instrumentos de regulación directa (command and control) y los de incentivo de mercado o simplemente económicos (market based incentives), los que son aplicados por el gobierno. Los primeros obligan al cumplimiento de un determinado estándar o tecnología a todas las fuentes involucradas en la regulación. Los instrumentos económicos buscan cambiar el comportamiento de los agentes económicos internalizando los costos ambientales por medio de un cambio de los incentivos que enfrentan los agentes. Incluyen por lo general los permisos transables, impuestos, depósitos reembolsables, etc. Sin embargo los instrumentos que promueven una mayor protección del ambiente y las presiones que reciben las empresas son hoy más sofisticados que esto, como se discute a continuación. Luego se presenta un caso ilustrativo del problema asociado a la selección de instrumentos de regulación.

\subsection{El Nuevo modelo de regulación ambiental}

Para analizar la forma en que se lleva hoy la regulación ambiental es conveniente considerar un modelo conceptual propuesto recientemente por 
el Banco Mundial (2002), que se presenta en la Figura $N^{\circ} 6$. Este modelo distingue entre tres instituciones/agentes que influyen sobre las fuentes emisoras: el mercado, la comunidad y el gobierno.

Los mercados crean incentivos para limitar las emisiones. Por una parte los consumidores con creciente conciencia ecológica exigen que los productos y servicios que compran sean amigables con el medio ambiente, idealmente de la cuna a la tumba del producto. Se han creado instrumentos específicos, en particular los sistemas de certificación. Entre éstos se distinguen los ecoetiquetados (por ejemplo, Nordic Swan, Swedish Environmental Choice Programme, Eco-label Award Scheme de la UE), que se preocupan del cumplimiento de ciertos criterios que aseguran que el producto sea amigable con el ambiente en cada una de sus etapas; y la certificación de que la gestión de la producción incorpora criterios de sustentabilidad (ISO 14001, Forest Stewardship Council [FSC]). Las organizaciones no gubernamentales (ONG) juegan un rol importante aquí al promover acciones específicas ante consumidores y productores para obligar a éstos a producir de manera menos contaminante. Los exportadores chilenos han sufrido estos problemas en carne propia, como se detalla en dos trabajos recientes, uno para la minería chilena y otro para el sector forestal ${ }^{15}$.

FIGURA N 6: EL NUEVO MODELO DE REGULACIÓN AMBIENTAL

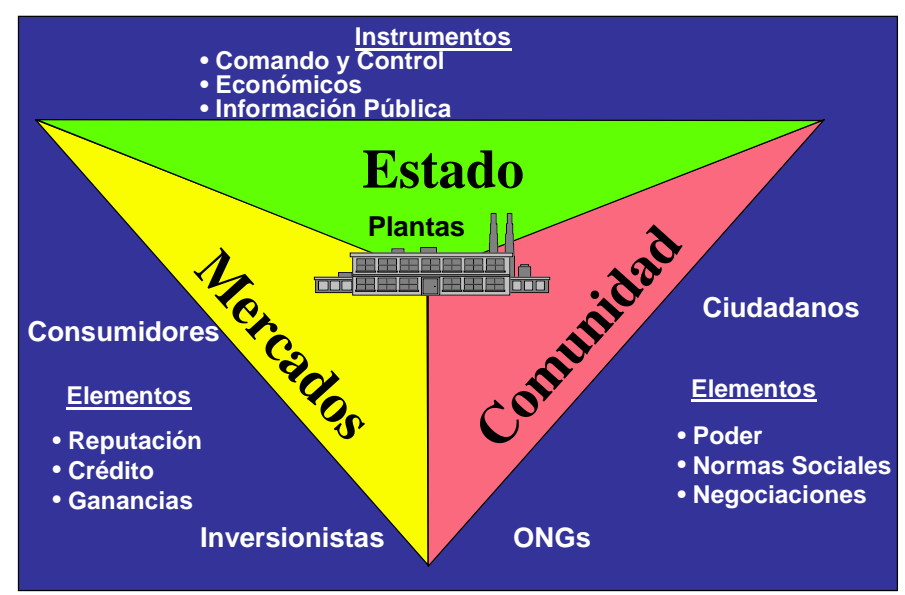

${ }^{15}$ Véanse O'Ryan y Ulloa (2001) y O'Ryan y Fierro (2001), respectivamente. 
Por otra parte, los inversionistas también presionan en muchos casos para asegurar que el comportamiento ambiental de las empresas en que invierten sea satisfactorio. De otra manera las sanciones y obligaciones que se pueden imponer a los emisores pueden disminuir la rentabilidad de los proyectos financiados. Esto no es un problema teórico: estudios recientes señalan que ante malas noticias en lo ambiental en la prensa, el precio de las acciones cae entre $1 \%$ y $2 \%$, incluso en Chile ${ }^{16}$.

Las comunidades por su parte influyen considerablemente en el comportamiento ambiental de las plantas industriales ${ }^{17}$. Donde hay regulaciones, éstas pueden influenciar a los políticos para apoyar regulaciones más estrictas. Donde no, ejercen una suerte de regulación informal al presionar a las firmas. Ante la amenaza de sanciones sociales, políticas o físicas, si no se compensa a la comunidad afectada o se reducen emisiones, los industriales negocian directamente con ésta. Por cierto, el resultado no tiene necesariamente que ver con un óptimo social. Los ciudadanos, las organizaciones sociales y religiosas y las ONG — nacionales e internacionales- juegan un rol importante. En Ralco, luego de diez años de litigio, se alcanzó un acuerdo entre la Endesa y cuatro familias pehuenches que permitirá ejecutar la central hidroeléctrica que aumenta en $18 \%$ la disponibilidad de energía del sistema interconectado central. Estas familias recorrieron el mundo buscando apoyo a su causa y el resultado final requirió la intervención del Gobierno al más alto nivel ${ }^{18}$. La economía política de esta relación y sus implicancias para el logro de un resultado eficiente están recién apareciendo.

Por su parte, el gobierno dispone de los instrumentos de regulación directa y económicos antes mencionados para promover sus objetivos ambientales. La discusión y la investigación en este ámbito se han ampliado desde la contraposición de instrumentos económicos y de regulación directa con una óptica de eficiencia, hasta preguntas sobre las otras dimensiones por considerar al momento de aplicar un instrumento: su efectividad, y los aspectos administrativos, legales e institucionales involucrados. Aparte de la dimensión costo-efectividad, la decisión del instrumento a aplicar incluye sus impactos distributivos — ganadores y perdedores-, los requerimientos de información, cambios legales requeridos, principios de gestión ambiental que se deben modificar, factibilidad política, costos de fiscalización y monitoreo, facilidad en su aplicación e incertidumbres presentes ${ }^{19}$.

\footnotetext{
16 Véase Dasgupta, Laplante y Mamingi (1997).

17 Véase, por ejemplo, Dasgupta, Lucas y Wheeler (1998).

18 Véase El Mercurio, 17 de septiembre, 2003, p. A1.

19 Véanse diversos estudios: Bohm y Russell (1985); OTA (1995); IPCC (1996);
} Richards (1998). 
Finalmente, ha surgido en la última década la posibilidad de ejercer presión por medio de la diseminación de información (information disclosure) sobre emisiones o desempeño ambiental. Esta posibilidad se relaciona directamente con las dos instituciones anteriores, ya que la información permite que la comunidad local, las ONG, inversionistas y consumidores conozcan mejor el desempeño ambiental. Por cierto, este instrumento es problemático de aplicar, ya que nada asegura que los resultados se relacionen con valores razonables para la industria afectada: los afectados pueden presionar por cero emisión, aun cuando ello no sea eficiente. Proper en Indonesia y EcoWatch en Filipinas son ejemplos de aplicaciones de este instrumento.

El nuevo modelo de regulación tiene una especial relevancia para los países en desarrollo que dependen del comercio exterior. Las restricciones ambientales externas y las fitosanitarias condicionan la política ambiental local; gran parte de ésta deja de ser endógena y está determinada por las exigencias internacionales. Es decir, por grupos de poder externos que influencian a los consumidores y a los gobiernos para aplicar normas que muchas veces son medidas de protección comercial. Nuevamente la economía política de la regulación ambiental juega un papel preponderante, pero ahora los jugadores son externos y nosotros perdemos grados de libertad para entrar en este juego. Los mercados externos reaccionan a presiones locales que generalmente no tienen que ver con el bienestar mundial y ni siquiera local. El resultado es que las empresas nacionales se ven sometidas a regulaciones más exigentes que las que un análisis costobeneficio sostendría.

\subsection{Caso 4: Estrategia para el control de sustancias agotadoras de la capa de ozono: no exactamente lo que ordenó el doctor ${ }^{20}$}

Los criterios para seleccionar instrumentos son un tema de discusión teórica y de aplicación importante. Este caso lo ilustra por medio de una aplicación específica.

En marzo de 1990 Chile ratificó el Protocolo de Montreal sobre Sustancias que Agotan la Capa de Ozono (SAO), comprometiéndose primero a reducir y luego a eliminar su consumo. Como muchos países en desarrollo, Chile no había definido hasta el año 2000 una estrategia para cumplir dicho protocolo. Los países desarrollados, por su parte, han optado por diversas estrategias por lo general combinando el uso de regulación

${ }^{20}$ Resumido a partir de O’Ryan, Ulloa y Asencio (1999). Disponible en www.dii.uchile.cl/progea/pub-en.htm 
directa e instrumentos de mercado. Por ello se trabajó con Conama para elaborar una propuesta específica.

Chile es básicamente un país importador de SAO. La sustancia más importante es el CFC-11 con un $38 \%$ del consumo $\mathrm{PAO}^{21}$, seguido por el CFC-12 (32\%) y luego el bromuro de metilo (BM, 22\%). Las demás sustancias tienen poco peso en el consumo $\mathrm{PAO}^{22}$. La importación de CFC está concentrada en pocas empresas importadoras. Con respecto a los usuarios finales de CFC, cerca del 55\% del consumo se concentra en empresas grandes y medianas y el resto está atomizado en empresas pequeñas, o con consumos eventuales, y entre técnicos de refrigeración. En total se estima que podrían existir más de 400 usuarios finales de CFC.

En este contexto, es de interés responder preguntas como ¿qué atributos son relevantes para la autoridad ambiental al momento de seleccionar instrumentos que permitan cumplir las obligaciones contraídas en el protocolo? ¿Cuáles son los costos de cumplir con las reducciones comprometidas? ¿Hace una diferencia significativa el aplicar instrumentos flexibles? Los economistas prefieren usar instrumentos flexibles porque son costoefectivos. Sin embargo, los reguladores también tienen otros atributos que valoran al momento de elegir un instrumento específico: la efectividad, la simplicidad administrativa, legal e institucional, y las posibilidades de monitoreo y fiscalización.

\section{Escenarios de Consumo de CFC: 1997-2010}

Se definieron cinco escenarios potenciales para el consumo de CFC-11 y CFC-12 que combinan posibles tasas de consumo, niveles de reconversión de empresas usuarias y niveles de uso del Fondo Multilateral del Banco Mundial para la reconversión de empresas. La Figura $\mathrm{N}^{\circ} 7$ presenta los resultados, comparados con las obligaciones contraídas por Chile.

Se puede concluir que es necesario generar una estrategia que haga factible acercarse al escenario optimista, de modo que Chile cumpla con las obligaciones que le impone el protocolo respecto de los CFC. Adicionalmente, será necesario definir instrumentos que permitan asegurar el cumplimiento de las metas de los años 2007 y 2010, que se prevén como las más difíciles de lograr.

${ }^{21}$ El potencial de agotamiento de la capa de ozono (PAO) de un compuesto es una medida de su capacidad para destruir ozono estratosférico. Es una medida relativa en que se define el PAO del CFC-11 como 1,0, y el de los demás compuestos en base a este punto de referencia.

${ }^{22}$ Con excepción de los HCFC (que pesan poco en el total PAO), se espera que sigan disminuyendo. 
FIGURA N ${ }^{\circ} 7: \quad$ COMPARACIÓN DE ESCENARIOS CON OBLIGACIONES

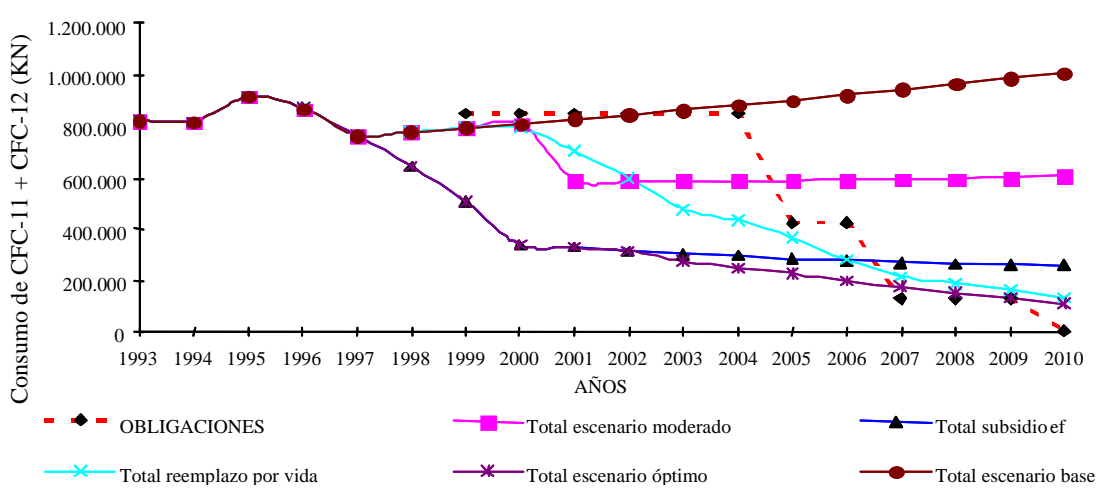

Evaluación cualitativa de opciones regulatorias

En base a la experiencia internacional y a las características específicas del caso chileno se ha considerado interesante evaluar cualitativamente cinco instrumentos de regulación: tres de regulación directa y dos de mercado. Los primeros incluyen normas de producto, que regulan la producción e importación de productos que pudieran contener o haber sido fabricados con sustancias controladas; prohibición de importación de sustancias o grupos de ellas; y cuotas de importación, que permiten que agentes autorizados importen un total máximo de sustancias (distinto de cero). Las regulaciones de mercado consideradas incluyen: tarifas a las importaciones, mediante las cuales se cobra una sobretasa a la internación de sustancias, y un sistema de permisos de importación transables (SPIT), que consiste en la asignación de permisos de importación libremente transables entre los usuarios de estas sustancias. El Cuadro $\mathrm{N}^{\circ} 4$ resume la evaluación cualitativa de cada opción.

Es claro que no hay ninguna opción dominante. Sin embargo, al comparar los SPIT con las cuotas de importación y las tarifas, se concluye que aquéllos tienen ventajas. $\mathrm{Si}$ bien todas las opciones requieren una ley, los SPIT son eficientes (cosa que no sucede con las cuotas) y efectivos (lo que no sucede con las tarifas). En particular, reducen fuertemente la incertidumbre tanto para los usuarios como para el regulador. Además, la potencial aplicación de SPIT no parece contar con un rechazo de parte de la autoridad económica, mientras que la aplicación de una tarifa es más sensible. Por otra parte, la opción de prohibir en forma secuencial ciertas 


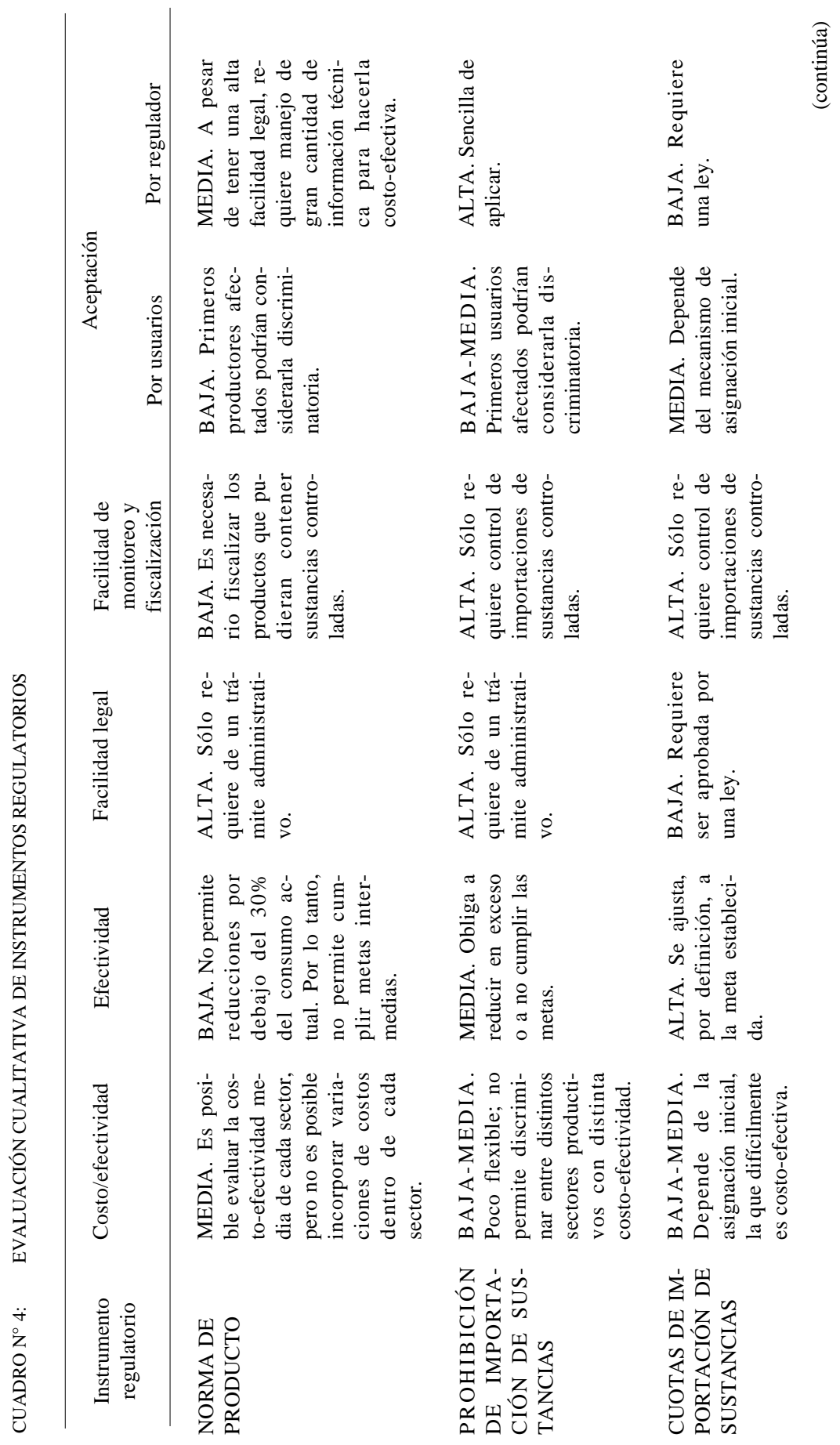



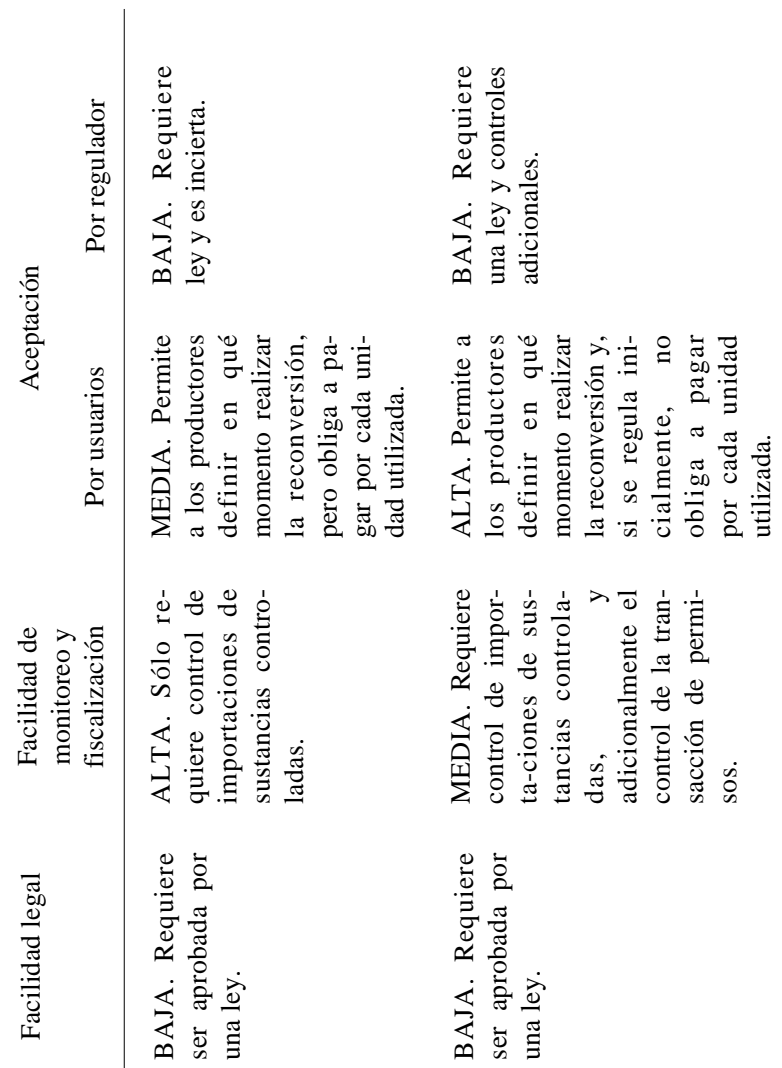

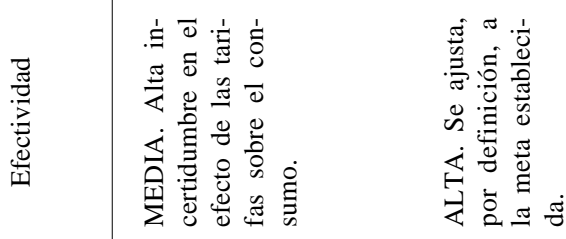

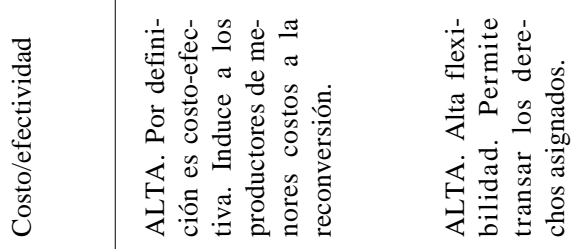

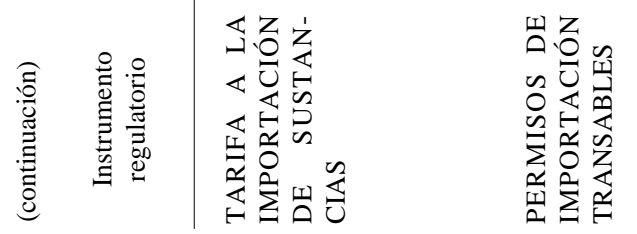


sustancias tiene el atractivo de ser fácil de implementar y de controlar. Considerando que la reconversión de la industria usuaria del CFC-11 presenta costos menores que la usuaria de CFC-12, debiera prohibirse primero el CFC-11 y luego el CFC-12. Las fechas de reducción relevantes son el 2005 (50\%) y el 2007 (15\%), por lo que es interesante generar y evaluar un escenario que cumpla, vía prohibiciones, con estas metas.

Estas conclusiones generales se discutieron con el equipo Conama encargado de definir la regulación, y a partir de ellas, y de las prioridades del regulador se optó por evaluar cuantitativamente los siguientes instrumentos: SPIT, prohibición adelantada (que permita cumplir en las fechas previstas del acuerdo), prohibición, normas de productos.

\section{Evaluación cuantitativa de opciones elegidas}

El Cuadro $\mathrm{N}^{\circ} 5$ presenta los costos de cada opción regulatoria para tres escenarios.

CUADRO N ${ }^{\circ}$ 5: $\quad$ COSTOS DE LAS OPCIONES REGULATORIAS PARA CADA ESCENARIO

\begin{tabular}{|c|c|c|c|}
\hline & $\begin{array}{c}\text { Escenario } \\
\text { pesimista } \\
\text { VPN } \\
\text { [US\$ millones] }\end{array}$ & $\begin{array}{c}\text { Escenario } \\
\text { moderado } \\
\text { VPN } \\
\text { [US\$ millones] }\end{array}$ & $\begin{array}{c}\text { Escenario } \\
\text { optimista } \\
\text { VPN } \\
\text { [US\$ millones] }\end{array}$ \\
\hline Prohibiciones: 2005-2010 & $8,7^{* *}$ & $3,6 * *$ & $1,1^{*}$ \\
\hline Norma de producto & $11,4 * *$ & $2,9 * *$ & $0,8^{*}$ \\
\hline SPIT & 14,4 & 5,4 & 1,1 \\
\hline Prohibiciones adelantadas: 2005-2007 & 18,8 & 11,0 & 4,9 \\
\hline
\end{tabular}

Los ahorros de los costos de aplicar un SPIT (US\$ 4 millones a US\$ 5 millones) no son muy significativos. Discusiones con las autoridades de Conama señalan que este gasto adicional es un "mal menor" si con ello se evita llevar la discusión de la estrategia al Congreso, lo que efectivamente sucede al aplicar prohibiciones adelantadas. La autoridad tampoco estima que sean importantes los usos potenciales que se pueden dejar de realizar por adelantar la prohibición de CFC12 al 2007. No hay quien abogue por ellos si se plantea esto con suficiente antelación. Por ello, al 
sopesar tanto los antecedentes cuantitativos como cualitativos, la autoridad se inclina por aplicar prohibiciones por sustancia, adelantando la de CFC12 al 2007. ¡No exactamente lo que ordenó “el doctor”!23

\section{ANÁLISIS DE EQUILIBRIO PARCIAL VS. EQUILIBRIO GENERAL}

En general, para analizar diferentes políticas ambientales se usan modelos de equilibrio parcial. Estos modelos tienen la gran ventaja de que requieren poca información y permiten analizar en detalle el o los sectores afectados directamente. Sin embargo, estos modelos no capturan los efectos sobre el resto de los agentes y sectores de la economía. Los modelos de equilibrio parcial no permiten encontrar respuestas acerca de los impactos en otros sectores. Los impactos sobre el empleo, el ingreso, los sectores más afectados, los ganadores y perdedores indirectos no son analizados en estos modelos.

Los modelos de equilibrio general resuelven en parte el problema, pues permiten una visión global de la economía integrando consumidores y productores, además de las acciones del gobierno en un solo modelo. Desgraciadamente, los modelos de equilibrio general teóricos son por lo común muy simples y no representan adecuadamente las interrelaciones económicas entre diferentes agentes en forma realista, o bien asumen muy pocos sectores productivos. Los modelos de equilibrio general computables (EGC) permiten integrar un mayor número de sectores e incorporar adecuadamente las relaciones económicas entre productores y consumidores, además de utilizar datos empíricos provenientes de las cuentas nacionales del país. Si bien estos modelos requieren esfuerzos notablemente superiores en su desarrollo, debido al enorme caudal de información que debe determinarse y el tiempo para su desarrollo en sí, permiten apreciar en forma "más realista" los impactos que se generan en la economía del país. Por ello es deseable tener un modelo con estas características que permita complementar los análisis de equilibrio parcial. Los modelos EGC siguen el tradicional flujo circular de la renta que en este caso se resume en la Figura $\mathrm{N}^{\circ} 8$, según la cual se observan las interrelaciones entre los diferentes agentes económicos.

Las principales tres etapas en la construcción de un modelo EGC son las siguientes:

1. Desarrollo del modelo teórico que rige a la economía (supuestos de competencia de los mercados locales y extranjeros, funciones de producción y consumo, intertemporalidad, etc.).

\footnotetext{
${ }^{23}$ Es decir, los economistas preocupados por la eficiencia.
} 
FIGURA $\mathrm{N}^{\circ}$ 8: $\quad$ FLUJO CIRCULAR DE LA RENTA

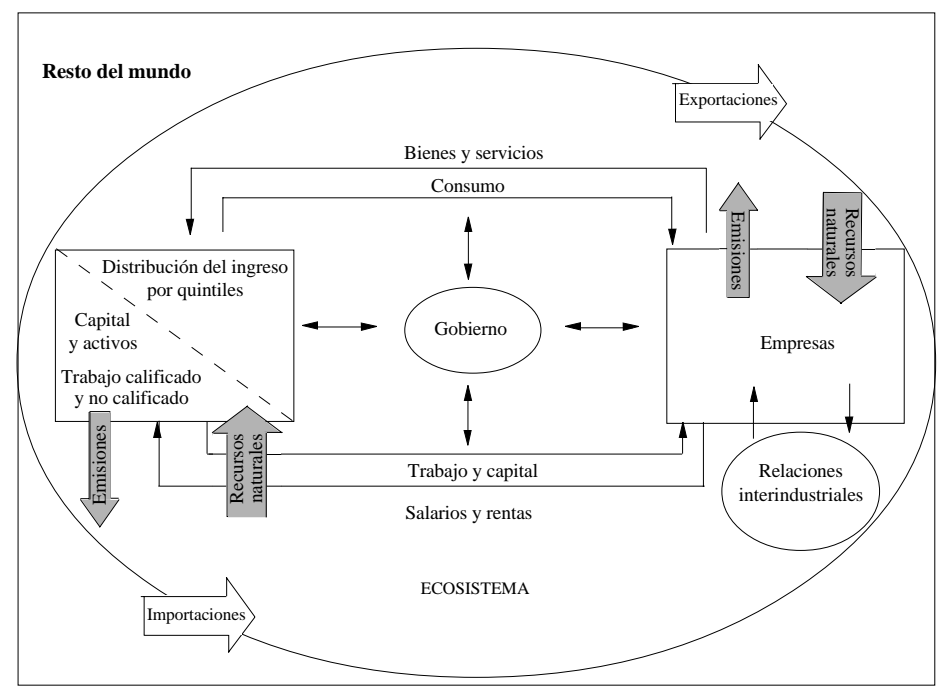

2. Especificación de los agentes considerados y su desglose (factores productivos, sectores, socios comerciales, etc.).

3. Construcción/adaptación del modelo a la problemática específica que se desea explorar.

\subsection{El modelo Ecogem-Chile}

Para realizar análisis de equilibrio general se ha adaptado un modelo que permite examinar conjuntamente los impactos derivados de ciertas reformas impositivas, con los impactos en general sobre la economía derivados de acuerdos comerciales. Esto permite desarrollar investigación en diversos ámbitos, en particular impuestos/subsidios ambientales y de comercio y medio ambiente. Para ello se ha trabajado con una adaptación del modelo de la OECD (Beghin, et al., 1996) que hemos llamado EcogemChile. Es un modelo estático, cuyas principales características son el gran número de especificaciones que posee. Su posibilidad de incluir múltiples sectores productivos, tipos de trabajo, hogares agrupados por ingreso, socios comerciales y una amplia gama de instrumentos de política tributaria es una de ellas. 
La producción se modela mediante funciones CES/CET, elasticidad de sustitución/transformación constante, anidadas. Por el lado de la producción (XP), el primer nivel se escoge mediante una CES entre una canasta de insumos intermedios no energéticos y una canasta de factores (capital y trabajo) e insumos energéticos (KEL). KEL es un bien compuesto de capital (K), energía (E) y trabajo (L). Por el lado de los factores se divide la canasta de capital-energía y el trabajo mediante una nueva CES, y sucesivamente se separa la energía del capital, asumiéndose siempre función CES para la sustitución tanto entre factores como dentro de ellos (tipos de trabajo, energía y capital) ${ }^{24}$. ND representa insumos no energéticos. PKEL y PND son los precios compuestos del KEL y ND para cada sector i. Asumiendo rendimientos constantes a escala en la producción, cada sector produce minimizando costos, sujeto a la función de producción de la siguiente manera:

$$
\begin{gathered}
\min P K E L_{i} K E L_{i}+P N D_{i} N D_{i} \\
\text { s.a. } \\
X P_{i}=\left[a_{k e l, i} K E L_{i}^{\rho_{i}^{p}}+a_{n d, i} N D_{i}^{\rho_{i}^{p}}\right]^{i /} \rho_{i}^{p}
\end{gathered}
$$

Por el lado de los hogares, éstos distribuyen su ingreso entre ahorro y consumo mediante una función de utilidad ELES (Extendend Linear Expenditure System). La forma en la cual se incorpora el ahorro (dividido por un índice de precios de los demás bienes) neutraliza parcialmente la sustitución entre ahorro y consumo, debido a que el precio del ahorro es una ponderación de los precios de todos los demás bienes. Esta función además considera consumos mínimos de subsistencia a la stone-geary. Se pueden distinguir diferentes tipos de hogares por ingreso (quintiles o deciles), según información de base disponible. El consumidor $h$ resuelve el siguiente problema:

$$
\begin{aligned}
& \max \quad U=\sum_{i=1}^{n} \mu_{i} \ln \left(C_{i}-\theta_{i}\right)+\mu_{s} \ln \left(\frac{S}{c p i}\right) \\
& \text { s.a. } \quad \sum_{i=1}^{n} P C_{i} C_{i}+S=Y D \quad \text { y } \quad \sum_{i=1}^{n} \mu_{i}+\mu_{s}=1
\end{aligned}
$$

${ }^{24} \mathrm{KEL}$ es un bien compuesto de K, E y L, que luego mediante una nueva CES se divide en KE y L, y luego en tipos de L y en K y E. 
Otros elementos: Una vez definidas las demandas intermedias y la de los hogares, sólo resta incluir el resto de las demandas finales, i. e., inversión, gasto de gobierno, variación de existencias y márgenes de distribución (domésticas y sobreimportaciones). La demanda final de cada ítem se define como porciones fijas de la demanda final total.

En cuanto a las finanzas públicas, se tienen distintos tipos de impuestos y transferencias. En el modelo se definen: impuestos al trabajo (diferenciado por categoría ocupacional), a las firmas (utilidades), al ingreso (diferenciado por quintil o decil), los cuales son directos. Además se definen aranceles y subsidios a las importaciones, impuestos y subsidios a las exportaciones (diferenciados por sector) e IVA (nacional e importado, así como por sector). Finalmente, el modelo además incluye los impuestos/ subsidios sectoriales indirectos (a los derivados del petróleo, a las bebidas y al tabaco, el subsidio al carbón, etc.) y transferencias desde y hacia el exterior y los hogares por parte del gobierno.

En la incorporación del sector externo se utiliza el supuesto de Armington, que permite sustitución imperfecta entre bienes y servicios nacionales e importados. Así también se usa una función CES anidada para representar la canasta nacional e importada. A su vez, para la oferta de producción nacional, ésta recibe un tratamiento similar al de la demanda, incorporando ahora una CET para distinguir entre el mercado nacional y el de exportaciones.

\subsection{Caso 5: Impuestos ambientales}

Durante el desarrollo de esta línea de investigación se han realizado diversas aplicaciones. Sin embargo cabe destacar dos. La primera consiste en explorar el impacto de los impuestos y subsidios que afectan al medio ambiente en Chile. El segundo grupo de aplicaciones versa sobre el tema de comercio y medio ambiente, en particular los impactos de los acuerdos de libre comercio sobre el medio ambiente.

Algunos resultados de la primera área de trabajo se resumen a continuación. El análisis que se realiza consiste en evaluar cuantitativamente el impacto de introducir impuestos ambientales en Chile. Para ello se evalúan dos alternativas: un impuesto a las emisiones de PM10 y otro impuesto a los combustibles derivados del petróleo. En ambos casos lo que se busca es reducir las emisiones de PM10 en aproximadamente 10\%.

Los resultados se resumen en el Cuadro $\mathrm{N}^{\circ} 6$ y son ilustrativos del tipo de análisis que permite este tipo de enfoque. Al observar los resultados de la simulación, lo primero que se observa es que para el caso de un 
impuesto a los derivados del petróleo los efectos son más negativos que en el caso de un impuesto a las emisiones. Asimismo, esto repercute en el resto de los sectores, haciendo de ésta una política más onerosa en términos globales. El ingreso real cae para todos en ambos casos. A su vez el ahorro se ve negativamente afectado por estas políticas. En el caso de las emisiones de contaminantes se tiene que estos resultados se reducen para el PM10 en cerca del $10 \%$.

CUADRO N ${ }^{\circ}$ 6: $\quad$ IMPACTOS DE INCLUIR IMPUESTOS AL PM10 Y DERIVADOS DEL PETRÓLEO

\begin{tabular}{|c|c|c|c|}
\hline \multicolumn{2}{|c|}{ Impactos } & \multicolumn{2}{|c|}{ Simulación de impuestos } \\
\hline & & PM10 & Derivados del petróleo \\
\hline \multirow{5}{*}{ 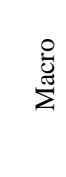 } & PIB real demanda final & $-0,2 \%$ & $-0,5 \%$ \\
\hline & Consumo & $-0,2 \%$ & $-0,8 \%$ \\
\hline & Inversión & $-0,2 \%$ & $0,4 \%$ \\
\hline & Exportaciones & $-1,5 \%$ & $-2,0 \%$ \\
\hline & Importaciones & $-1,6 \%$ & $-2,0 \%$ \\
\hline \multirow{11}{*}{ 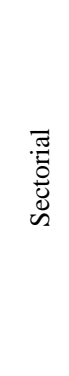 } & Refinería petróleo & $-11,2 \%$ & $-20,6 \%$ \\
\hline & Petróleo y gas natural & $-4,5 \%$ & $-7,4 \%$ \\
\hline & Otros transportes & $-3,4 \%$ & $-3,0 \%$ \\
\hline & Transporte terrestre & $-2,2 \%$ & $-2,3 \%$ \\
\hline & No renovables & $-0,7 \%$ & $-0,5 \%$ \\
\hline & Alimentos & $0,6 \%$ & $0,0 \%$ \\
\hline & Textiles & $1,6 \%$ & $0,6 \%$ \\
\hline & Construcción & $-0,2 \%$ & $0,3 \%$ \\
\hline & Gas & $2,3 \%$ & $2,2 \%$ \\
\hline & Electricidad & $1,3 \%$ & $1,0 \%$ \\
\hline & Agua & $3,3 \%$ & $2,0 \%$ \\
\hline \multirow{5}{*}{ 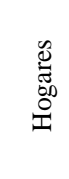 } & Ingreso disponible real Q1 & $0,2 \%$ & $-0,5 \%$ \\
\hline & Ingreso disponible real Q2 & $0,2 \%$ & $-0,5 \%$ \\
\hline & Ingreso disponible real Q3 & $0,1 \%$ & $-0,6 \%$ \\
\hline & Ingreso disponible real Q4 & $-0,1 \%$ & $-0,8 \%$ \\
\hline & Ingreso disponible real Q5 & $-0,5 \%$ & $-1,0 \%$ \\
\hline \multirow{5}{*}{ 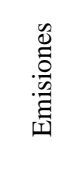 } & $\mathrm{SO}_{2}$ & $-11,1 \%$ & $-10,9 \%$ \\
\hline & $\mathrm{NO}_{2}$ & $-11,0 \%$ & $-10,8 \%$ \\
\hline & $\mathrm{CO}$ & $-3,0 \%$ & $-3,1 \%$ \\
\hline & $\mathrm{COV}$ & $-1,7 \%$ & $-3,6 \%$ \\
\hline & PM10 & $-10,0 \%$ & $-9,7 \%$ \\
\hline
\end{tabular}




\subsection{Conclusiones y futuros desarrollos de la línea}

El desarrollo del modelo Ecogem-Chile permite analizar una variada gama de políticas públicas y su impacto en los diferentes agentes económicos. Cabe señalar que, como todo modelo, es imperfecto desde su concepción, pues considera un conjunto de supuestos (como cualquier otro modelo) que son siempre criticables. Sin embargo, al hacer explícitos estos supuestos, se pueden llevar a cabo análisis útiles en especial para los tomadores de decisión. Por otra parte, esto también permite modificar dichos supuestos en etapas posteriores o por parte de otros investigadores si se cree necesario.

Entre las falencias del modelo actual se cuenta su estaticidad, es decir, el hecho de que trabaje con un modelo estático, obviando las relaciones dinámicas de la economía, en especial la inversión. Para ello se sigue trabajando actualmente en el desarrollo de un modelo dinámico que permita capturar dichas interrelaciones de mediano y largo plazo. Éstas son fundamentales en políticas que se consideran tendrán impactos de este período temporal, como son las políticas con impacto en la sustentabilidad del desarrollo, o el crecimiento de largo plazo.

Otra falencia en que se está trabajando es la estimación de parámetros del modelo, en especial todas las elasticidades que éste emplea. Como todo modelo de EGC, éste también es fuertemente criticado por utilizar un número importante de parámetros que con frecuencia no se estiman estadísticamente. En este sentido, se está trabajando para disminuir (ojalá eliminar) los parámetros no estimados en el modelo.

Finalmente, un tema adicional en el que se está trabajando es la incorporación de la calidad ambiental en la función de utilidad, con el fin de incorporar las preferencias de los consumidores por una mejor calidad ambiental, y con ello mejorar de modo sustancial el análisis de políticas ambientales con el modelo en cuestión. Esta área es tal vez, en los modelos EGC, la más novedosa.

\section{CONCLUSIONES Y COMENTARIOS FINALES}

El toolkit de los economistas estaba bien preparado a comienzos de los noventa para guiar la regulación ambiental. Chile ha seguido en la última década la evolución observada en diversos países desarrollados: primero regulación directa, luego el uso de instrumentos económicos, y la creciente incorporación de evaluaciones de costos $\mathbf{y}$ beneficios. Por ejem- 
plo, los Planes de Descontaminación y Normas deben realizar un análisis costo-beneficio para su aplicación. Si bien ello se hace de manera simple, deja de manifiesto el interés por incorporar los aspectos económicos en la toma de decisiones, tanto en la selección de instrumentos como en la definición de las metas por lograr. Cabe destacar que en esto somos más ambiciosos incluso que en Estados Unidos, donde por ley no se pueden considerar los aspectos económicos al aplicar normas que afectan a la salud. El caso de la regulación del arsénico es un buen ejemplo del cambio de mentalidad observado, ya que se normó considerando diversas dimensiones, no sólo los impactos en salud, como era tradicional.

Sin embargo, es fundamental incorporar más evaluaciones empíricas que permitan asegurar que las políticas aplicadas sean relativamente eficientes y eficaces. Tales evaluaciones deben iluminar respecto de la conveniencia de aplicar determinados instrumentos, por ejemplo, permisos transables para aire y agua. Deben también incorporar las implicancias distributivas y sectoriales de cada política, para así entender mejor las reacciones esperables y la economía política detrás de éstas. Para estas evaluaciones en este campo es común tener que analizar más de un mercado a la vez, lo que obliga al uso de modelos econométricos sectoriales con ecuaciones que describan el comportamiento de mercados específicos. El uso de pesticidas o el impacto de regular un contaminante urbano son ejemplo de ello. En algunos casos las evaluaciones de equilibrio general son apropiadas, en particular si se busca evaluar políticas que cruzan los principales sectores económicos (impuestos, tratados de libre comercio).

El diseño e implementación de los instrumentos debe mejorarse. Cuando el diseño es insuficiente $-\mathrm{o}$ inapropiado para el problema específico- se hace necesario modificar constantemente los instrumentos y eso genera incertidumbre regulatoria. Además, una inadecuada implementación implica crecientes costos de transacción. Con ello los instrumentos pierden credibilidad y no operan de manera eficiente, en particular los instrumentos económicos. Es común observar en la política ambiental que instrumentos interesantes se aplican mal y por tanto sus resultados son deficientes. Normalmente se desecha el instrumento (y no a quienes los aplicaron), aun cuando si bien concebidos y bien implementados pudieron ser eficientes. En otros casos se insiste con un instrumento inapropiado para el problema que se aborda.

Chile ha avanzado poco en cuanto al "hacer cumplir" (enforcement). El tipo de sanciones aplicables y los montos involucrados por lo general no se relacionan con lo necesario para incentivar el cumplimiento. 
Hace falta mayor investigación en este campo, la que está desarrollándose en forma muy incipiente.

Lo anterior implica que es necesario conocer los mercados con los que se está trabajando. No bastan las recetas simplistas de modelos de equilibrio parcial. ¡Para ello, los economistas deben salir a terreno! Además se requiere una mayor capacidad para trabajo interdisciplinario (economistas, ingenieros, abogados), mejor información y mejores modelos físicos y económicos.

En los últimos cinco años se han desarrollado los acuerdos de producción limpia (enfoque voluntario), que han permitido poner bajo control a algunos sectores que con otro tipo de instrumentos serían ineficaces debido a las dificultades de monitoreo y fiscalización. Hay un interesante campo de investigación futura en esta línea que identifica aquellos sectores para los que este tipo de instrumento es más aplicable. Similarmente, hay un amplio espacio para estudiar la conveniencia de aplicar instrumentos de diseminación de información, en especial cuando se estima costoso o difícil el hacer cumplir ciertas regulaciones. Por ahora la teoría económica ofrece pocas luces respecto de cuándo conviene aplicarlos, qué forma deben tomar y su comparación con la aplicación de instrumentos más tradicionales de regulación.

Un campo donde Chile ha sido extremadamente descuidado es el de las exigencias ambientales internacionales a las que se ven sometidas las exportaciones. Los principales sectores exportadores - y los más dinámicos de la economía-, tales como el salmonero, el forestal y el minero, están amenazados por estas exigencias. La aplicación del principio precautorio, y la acción de las ONG, empresas competidoras de nuestros productos, gobiernos y grupos de consumidores organizados, en forma creciente, presionan por un "manejo sustentable" de los recursos y que su uso no genere riesgos. La definición de qué se entiende por ello es difusa y queda en manos de instituciones que tienen intereses propios (distintos de maximizar el bienestar mundial). Hay crecientes exigencias de una certificación ambiental que asegure que el producto sea amigable con el ambiente en todas las etapas de su ciclo de vida. Estos instrumentos son también definidos por instituciones externas con intereses propios. Ello es una forma novedosa de proteccionismo que puede tener implicancias muy negativas para Chile. Hay, por cierto, en todas estas definiciones un importante juego de intereses. Entender la economía política que está detrás es crítico para diseñar las instituciones, políticas e instrumentos que permitan defender nuestras exportaciones.

Finalmente, hacemos un llamado a entusiasmar a nuestros estudiantes para que investiguen en temas de manejo de recursos. Este campo está 
prácticamente virgen, por ejemplo, en un tema tan relevante como el del cobre. No es lógico que en este campo haya muchas veces más trabajos publicados por investigadores de otros países.

Estamos convencidos de que veremos en forma creciente que la aplicación de buena economía a los problemas ambientales será una forma en que los académicos de Latinoamérica publiquen en los mejores journals del área: Journal of Environmental Economics and Management, Land Economics, Canadian Journal of Economics, American Journal of Agricultural Economics, Environmental and Resources Economics, Environment and Development Economics, etc. ${ }^{25}$.

\section{REFERENCIAS}

Arrow, K.; P. Dasgupta y K. G. Mäler: "Welfare Economics in Imperfect Economies". Documento de trabajo preparado en visita de los dos primeros autores al Beijer International Institute of Ecological Economics, Estocolmo, Suecia, 2002.

Banco Mundial: "Armonización de la Actividad Industrial con el Medio Ambiente: Nuevas Funciones de la Comunidad, el Mercado y el Gobierno". Coedición con Alfaomega Colombiana S. A., mayo, 2002.

Beghin, John, Sébastien Dessus, David Roland-Holst y Dominique van der Mensbrugghe: "General Equilibrium Modelling Of Trade And The Environment". Technical Paper № 116, OECD Development Centre, 1996.

Bohm y Russell: "Comparative Analysis of Alternative Policy Instruments". En A. Kneese y J. Sweeney (eds.), Handbook of Natural Resources and Energy Economics, Vol. I. Amsterdam: North Holland, 1985.

Dasgupta, Laplante y Mamingi: "Capital Market Responses to Environmental Performance in Developing Countries". World Bank Development Research Group Working Paper, N 1909 , octubre, 1997.

Dasgupta, Lucas y Wheeler: "Small Manufacturing Plants, Pollution and Poverty: New Evidence from Brazil and Mexico". World Bank Development Research Group Working Paper, $N^{\circ}$ 2029, diciembre, 1998.

El Mercurio: "Fin a 10 Años de Litigios por Central Ralco", 17 de septiembre, 2003, p. A1.

Holz, J. C. y Sánchez, J. M.: "Estimation of Unitary Costs of Mortality and Morbidity and its Application to Assess The Health Benefits of the Santiago Decontamination Plan". Documento no publicado, 2000.

IPCC (Intergovernmental Panel on Climate Change): Climate Change 1995: Economic and Social Dimensions of Climate Change. Cambridge, MA: Cambridge University Press, 1996.

${ }^{25}$ Cabe señalar que en junio de 2004 se realizó el Primer Congreso Latinoamericano y del Caribe de Economistas Ambientales y de Recursos, organizado por la recientemente creada Asociación Latinoamericana y del Caribe de Economistas Ambientales y de Recursos (ALEAR). Éste se constituyó formalmente en el Segundo Congreso Mundial de Economistas Ambientales y de Recursos realizado el 2002 en Monterrey, California. Todo lo anterior señala que ésta es una subdisciplina que está consolidándose en la región. 
Montero, J. P., J. M. Sánchez y R. Katz: "Análisis del Mercado de Emisiones de Material Particulado en Santiago". Estudios Públicos, 81 (verano 2001).

O'Ryan, Raúl: "Cost-Effective Policies to Improve Urban Air Quality in Santiago, Chile”. Journal of Environmental Economics and Management, 31, November, pp. 302-313, 1996.

O’Ryan, Raúl: “Actualización y Aplicación de Permisos de Emisión Transables a la Contaminación Atmosférica de la Región Metropolitana en el Contexto del Plan de Descontaminación". Informe Final Preparado para Conama, 1999.

O’Ryan, R., A. Ulloa y G. Asencio: "Strategy for Controlling Ozone-Depleting Substances in a Country that Imports Them: The Case of Chile". XVII Latin American Meeting of the Econometric Society, August 2-6, 1999, Cancún, México.

O’Ryan, Raúl y M. Díaz: "Risk-Cost Analysis For The Regulation Of Airborne Toxic Substances In a Developing Context: The Case Of Arsenic in Chile". Environmental and Resource Economics, Vol. 15, № 2, February, pp. 115-134, 2000.

O’Ryan, Raúl y G. Fierro: "Trade and the Environment: Forestry”. En R. Fischer (ed.), Latin America and the Global Economy. Export, Trade and the Threat of Protection. U.K.: Palgrave McMillan Press, 2001, pp. 158-197.

O’Ryan, Raúl y A. Ulloa: “Trade and the Environment: Mining”. En R. Fischer (ed.), Latin America and the Global Economy. Export, Trade and the Threat of Protection. U.K.: Palgrave McMillan Press, 2001, pp. 121-157.

O'Ryan, Raúl: "Emissions Trading in Santiago: Why Has It Not Worked, but Been Succesful?". Trabajo presentado en CATEP (Concerted Action for Tradable Emissions Permits) Workshop, marzo 24-25, Department of Economics, University College London, U. K., 2002.

OTA (Office of Technology Assessment): Assessing Contractor Use in Superfund: A Background Paper of OTA's Assessment on Superfund Implementation. U. S. Government Printing Office, Washington D. C., 1995.

Richards, K.: "Framing Environmental Policy Instrument Choice". School of Public and Environmental Affairs. Working Paper, Indiana University, julio 1998. 